\title{
Lithospheric Extension Near Lake Mead, Nevada: A Model for Ductile Flow in the Lower Crust
}

\author{
SARAH KRUSE ${ }^{1}$, MARCIA MCNUTT, JASON PHIPPS-MORGAN², AND LEIGH ROYDEN \\ Deparoment of Earth. Amospheric, and Planetary Sciences, Massachusetts Institute of Technology. Cambridge
}

\author{
BRIAN WERNICKE
}

Department of Geological Sciences, Harvard University, Cambridge, Massachusetzs

\begin{abstract}
Small variations in gravity anomalies and topographic elevation observed in areas that have undergone highly variable amounts of upper crustal thinning can be satisfactorily explained by ductile flow of lower crustal material under the proper conditions. In this study we examine the boundary between the unextended Colorado Plateau and a strongly extended domain in the Basin and Range Province in the Lake Mead (Nevada) region. Bouguer gravity and topography data suggest that both present and preextensional variations in crustal thickness between the unextended and extended regions are small. Analytic channel flow models show that viscosities required for ductile flow in a lower crustal channel to reduce discontinuities in crustal thickness associated with variable amounts of extension are highly dependent on the channel thickness and on the length scale of flow required. Finite element modeling of Newtonian flow and power law creep shows that flow over the length scale of the eastem Basin and Range ( $500 \mathrm{~km}$ or more) corresponding to upper crustal extension by a factor of 1.4-3 over 10 m.y. requires effective viscosities less than $10^{18}-10^{20} \mathrm{~Pa} s$ for ductile channels $10-25$ $\mathrm{km}$ thick. Flow over shorter length scales $(150 \mathrm{~km})$ may be accommodated with effective viscosities as high as $10^{21} \mathrm{~Pa}$ s. Modeling suggests that these effective viscosities may be sustained by lower crustal material deforming at laboratory-derived power law creep rates. The longer-scale flow may require elevated crustal temperatures (more than $700^{\circ} \mathrm{C}$ ), depending on the composition and material properties assumed. Under the boundary conditions assumed in this study the linear viscous flow models yield a satisfactory approximation to deformation by power law crecp. This work suggests that flow in the lower crust may be a viable mechanism for producing small variations in total crustal thickness between strongly extended and less cxtended regions, and thereby explaining the relative uniformity in gravily and topography between such regions.
\end{abstract}

\section{INTRODUCTION}

Many authors have noted that parts of the Basin and Range in the western United States have undergone considerable crustal extension or denudation, yet lie at comparable or only slightly lower elevations than nearby unextended areas [e.g., Wernicke, 1985; Mayer, 1986; Thompson and McCarthy, 1986; McKenzie, 1988; Block and Royden, 1990]. This observation precludes local (Airy) isostatic compensation, as the Airy model predicts that highly extended areas with thinned crust should be considerably lower topographically than unextended regions. Lithospheric warming associated with extension of the entire lithosphere (as in the pure shear model of McKenzie [1978]) will only partially offset the effect of crustal thinning on surface elevations. Differences in observed Bouguer gravity anomaìies between extended and unextended regions are also smaller than those predicted from Airy compensation for crustal thinning.

Several hypotheses have been proposed to explain the relatively small differences in topography and gravity anomalies between adjacent regions that have undergone very different amounts of

\footnotetext{
1Now at Physics Department, Eckerd College, St. Petersburg, Florida. 2Now at Scripps Institution of Oceanography, La Jolla, Califomia.

Copyright 1991 by the American Geophysical Union.
}

Paper number $90 \mathrm{JB} 02621$ 0148-0227/91/90JB-02621\$05.00 extension or upper crustal denudation. These include (1) a greater initial crustal thickness in areas subsequently extended [Coney and Harms, 1984]; (2) a difference in mantle properties beneath thinned and unextended crust [McKenzie, 1978]; (3) transport of material along discrete low angle shear zones [Wernicke, 1985]; (4) crustal underplating processes that add material to the base of the crust in thinned areas [Okaya and Thompson, 1986; Gans, 1987]; and (5) ductile flow of lower crustal material from regions of thicker upper crust toward regions of thinner upper crust [Spencer and Reynolds, 1984; Block and Royden, 1990; Wernicke, 1990]. Such flow reduces lateral variations in net crustal thickness.

We test these hypotheses in the area around Lake Mead, Nevada, which is a transition zone between highly extended crust of the Basin and Range and the adjacent unextended Colorado Plateau. The I.ake Mead area was chosen heranse (1) the offset in topographic elevation $(1000 \mathrm{~m})$ between the Basin and Range and Colorado Plateau provinces is smaller than that predicted by pure shear models assuming extension of the Basin and Range by a factor of 2 or more [Wernicke et al., 1988]; (2) detachment faults near the boundary dip beneath the extending region, reducing ambiguities in the nature of lower crustal mass transport; and (3) the present breakaway zone developed in the cratonic foreland of a Mesozoic thrust front, suggesting that variations in crustal thickness in this region were small prior to the onset of extension. In this study we focus primarily on the conditions under which ductile flow of lower crustal material can explain gravity and topography data in the Lake Mead area, with some additional analysis of other regions of variable amounts of extension. 


\section{TECTONIC SETTING}

The breakaway zone separating the Basin and Range and Colorado Plateau provinces of the western United States at the latitude of Lake Mead $\left(36^{\circ} \mathrm{N}\right)$ trends roughly north-south (Figure 1). The Basin and Range province to the west is characterized by topographic elevations of $500-1500 \mathrm{~m}$, anomalously high heat flow, and a crustal thickness of about $30 \mathrm{~km}$ [Allmendinger et al., 1987]. The Colorado Plateau to the east lies at a topographic elevation approximately $1000 \mathrm{~m}$ higher than the adjacent $B$ asin and Range and consists of flat-lying or gently dipping strata overlying crust estimated to be approximately $40 \mathrm{~km}$ [Thompson and Zoback, 1979] or $50 \mathrm{~km}$ thick [Hauser and Lundy, 1989].

The abrupt transition between the Basin and Range and Colorado Plateau provinces near Lake Mead is delineated by a 5-10-km-wide sedimentary basin that separates east-dipping normal-faulted blocks of the Basin and Range from the flat-lying strata at the western margin of the Colorado Plateau (Figures 1 and 2). The Gold Butte block, which lies between Lake Mead and the transition zone, may record $10-20 \mathrm{~km}$ of unroofing, where we define the magnitude of unroofing as the thickness of overlying material removed from rocks now at the surface (Figure 2) [Wernicke and Axen, 1988; J.E. Fryxell and B. Wernicke, Gold Butte Crustal Section, South Virgin Mountains, Nevada, submitted to Tectonics, 1990]. Along the breakaway zone, the detachment surface dips westward away from the Colorado Plateau beneath the tilted blocks of the eastem margin of the faulted region.

On the basis of reconstructions of the relative positions of structural units, extension across the entire Basin and Range at this latitude is estimated by Wernicke et al. [1988] to be between 190 and $300 \mathrm{~km}$ (an extension factor $\beta$ of 2 to 6 ) with net orientation about $\mathrm{N} 73^{\circ} \mathrm{W}$. Wernicke et al. suggest extension across the eastern part of the Basin and Range (between the Colorado Plateau and the Spring Mourtains) to be between 60 and $125 \mathrm{~km}(\beta=1.7$ to 7$)$ with

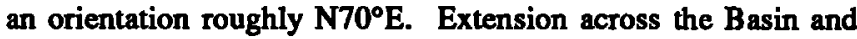
Range has occurred principally in the last 15 m.y. [Wernicke et al., 1988], while most extension in the Lake Mead region took place between 18 and $10 \mathrm{Ma}$ [Anderson et al., 1972; Bohannon, 1984].

Preextensional tectonic boundaries lie near, but do not coincide exactly with, the present breakaway zone. A latest PrecambrianPaleozoic hinge line for the Paleozoic continental margin trends northeast-southwest near Las Vegas, currently some $50-100 \mathrm{~km}$ west of the breakaway zone. East vergent thin-skinned Cretaceous thrust sheets are localized along this hinge zone [e.g., Burchfiel et al., 1974]. These thrust sheets restore close to the breakaway zone once extension is removed. However, the frontal thrust system is a decollement in Cambrian sediments for $50-60 \mathrm{~km}$ west of the hinge line. By analogy with unextended foreland thrust belts [e.g., Price, 1981], the preextensional Moho was probably flat or gently west dipping. Thus variations in crustal thickness across the Lake Mead area prior to extension were probably small.

Together, the unroofing of Gold Butte block and the extension estimates of Wernicke et al. [1988] suggest a minimum of $10 \mathrm{~km}$ of crustal thinning associated with extension in the area west of the Lake Mead transition zone. This minimum $10 \mathrm{~km}$ value corresponds to an extension factor of only 1.33 if preextensional crustal thicknesses were $40 \mathrm{~km}$. The geometry of unroofing of the Gold Butte block suggests that the width of the transition zone between the regions of thinned and unthinned upper crust is quite narrow, of the order of $50 \mathrm{~km}$ or less.

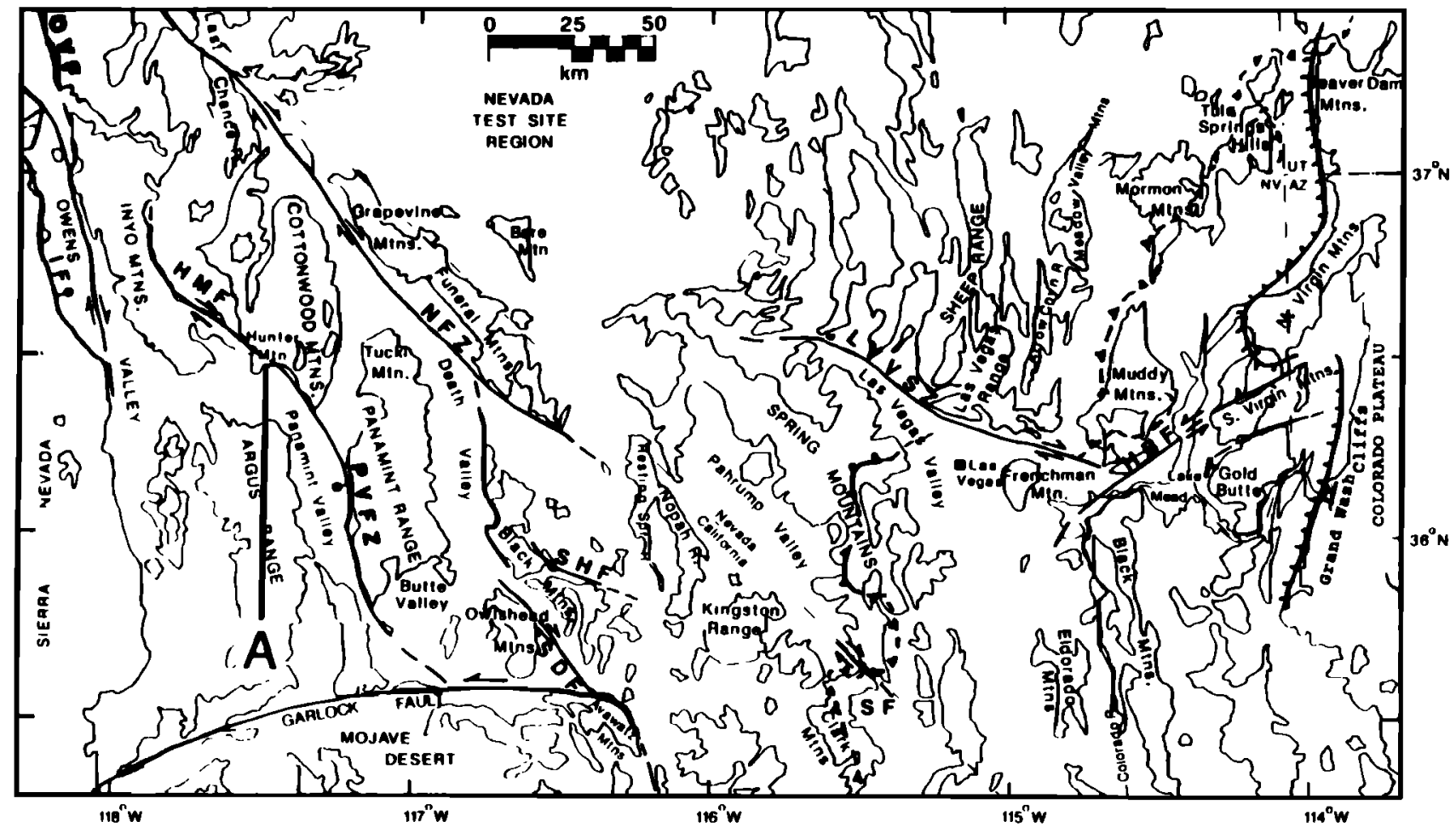

Fig. 1. Location map showing ranges in eastem Basin and Range at latitude of Lake Mead. N-S line marked A shows location of western end of profiles in Figure 4. T's shown near $36^{\circ} \mathrm{N}$ and $114^{\circ} \mathrm{W}$ indicate ends of profile in Figure 2. Barbed line indicates the location of the Mesozoic thrust front. Ticked line indicates the breakaway fault. Modified from Wernicke et al. [1988]. 


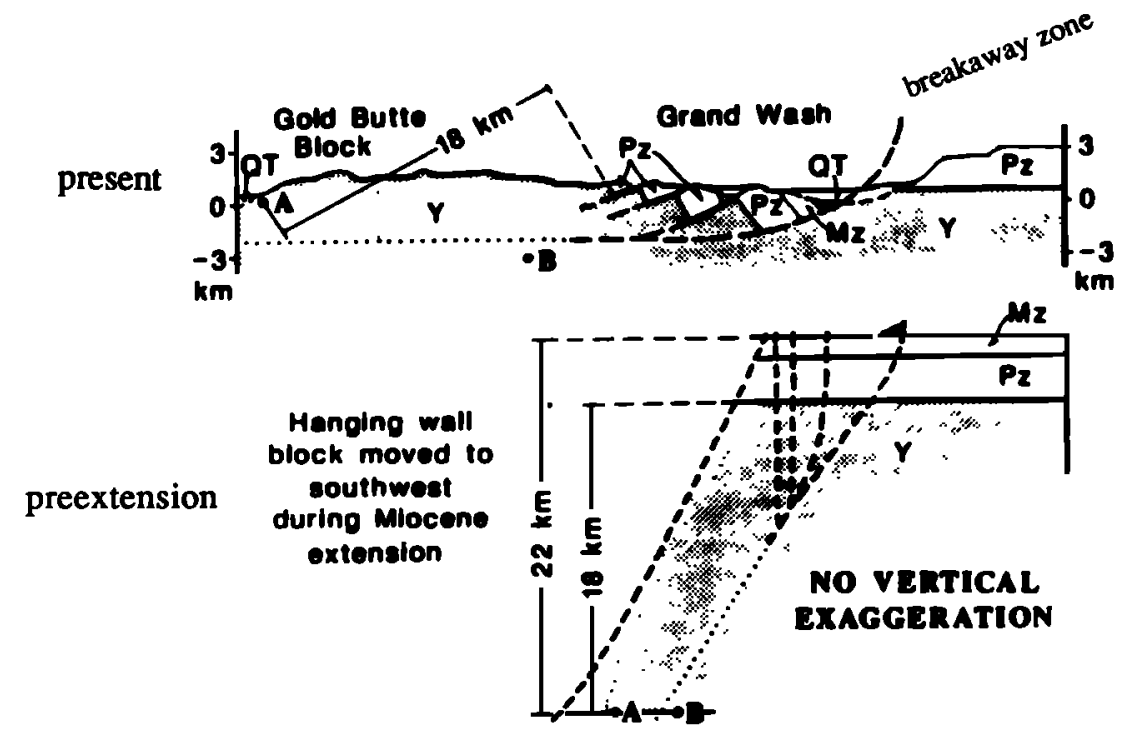

Fig. 2. Schematic cross section perpendicular to strike of transition zone at the latiude of Lake Mead showing inferred uplift of Gold Butue block. Location of profile shown in Figure 1. Modified from Wernicke and Axen [1988].

\section{TOPOGRAPHY, GRAVITY, SEISMIC, AND HEAT FLOW OBSERVATIONS}

Topographic elevations of $700 \mathrm{~m}$ in the Lake Mead region increase eastward across a transition zone less than $50 \mathrm{~km}$ wide to approximately $1500 \mathrm{~m}$ on the Colorado Plateau (Figures 3 and 4). Topographic elevations on the Colorado Plateau increase gently farther eastward to approximately $2000 \mathrm{~m}$ over the central plateau. Bouguer gravity anomalies of approximately $-120 \mathrm{mGal}$ over the Basin and Range grow increasingly negative eastward to approximately $-190 \mathrm{mGal}$ over the Colorado Plateau (Figures 3 and 4). The transition in gravity values occurs over a zone approximately $200 \mathrm{~km}$ wide.

Figure $5 a$ shows that the topography and Bouguer gravity together are compatible with a local (Airy) compensation model in which variations in elevation are compensated locally by deflections of the Moho. In this model the lower elevations over the Basin and Range are compensated by an approximately $5 \mathrm{~km}$ decrease in crustal thickness, assuming an upper crustal density of $2700 \mathrm{~kg} / \mathrm{m}^{3}$ and mantle density of $3300 \mathrm{~kg} / \mathrm{m}^{3}$. The topography and gravity data thus suggest variations in crustal thickness in the Lake Mead area that are smaller than the difference between the 30-km crustal thickness recorded in COCORP profiling across the central Basin and Range [Allmendinger et al., 1987] and the 40- or 50-km thickness of the Colorado Plateau interpreted from refraction and reflection data [Thompson and Zoback, 1979; Hauser and Lundy, 1989]. The gravity data are also compatible with a lithospheric flexural rigidity up to $10^{22} \mathrm{Nm}$ (effective elastic plate thickness up to about $15 \mathrm{~km}$ ) (Figure $5 a$ ).

No direct seismic observations of crustal structure are available for the Lake Mead transition zone. Data across the Basin and Range-Colorado Plateau transition at other locations, however, show a variety of features. A $3 \mathrm{~km}$ Moho offset is observed across the transition in west central Arizona [Hauser et al., 1987]. The COCORP transect across the transition zone at $40^{\circ} \mathrm{N}$ [Allmendinger et al., 1987] shows a region without strong reflectors in the transition zone separating an area in the Basin and Range with strong reflectors at $30 \mathrm{~km}$ depth from an area beneath the Colorado Plateau with strong reflectors at both 30 and $45 \mathrm{~km}$ depth.
An estimate of $P n$ velocities of $8.1 \mathrm{~km} / \mathrm{s}$ in the mantle lid beneath the Colorado Plateau [Beghoul and Barazangi, 1989] suggests that these velocities are significantly higher than the $7.8 \mathrm{~km} / \mathrm{s}$ values found in the Basin and Range. The length scale of the transition in velocities is undetermined.

Data compiled by Lachenbruch and Sass [1978] and Bodell and Chapman [1982] indicate heat flow in the Basin and Range (60-100 $\mathrm{mW} / \mathrm{m}^{2}$ ) is comparable to that observed on the periphery of the Colorado Plateau ( $\left.80-90 \mathrm{~mW} / \mathrm{m}^{2}\right)$. A lower average heat flow (60 $\mathrm{mW} / \mathrm{m}^{2}$ ) is observed in the interior of the Colorado Plateau. Assuming an exponential distribution of radioactive heat production with depth, Lachenbruch and Sass [1978] derive crustal geotherms of $25^{\circ}-30^{\circ} \mathrm{C} / \mathrm{km}$ in the Basin and Range. Their models suggest temperatures of $700^{\circ}-1000^{\circ} \mathrm{C}$ near the base of the crust at $30-40 \mathrm{~km}$ depth beneath the Basin and Range. Their work also suggests temperature differences at subcrustal depths between the Basin and Range and unextended lithosphere like the interior of the Colorado Plateau may be $200^{\circ}-500^{\circ} \mathrm{C}$. Differences in heat flow between these two provinces may, however, reflect a time lag associated with conduction of Cenozoic changes in the thermal regime at depth to the surface of the Colorado Plateau [Thompson and Zoback, 1979] rather than or in addition to present differences in subcrustal temperatures. The elevation of the Colorado Plateau and the presence of Cenozoic volcanism over both the Basin and Range and the Colorado Plateau near Lake Mead suggest that deep crustal and subcrustal temperatures may be unusually high in both provinces [Thompson and Zoback, 1979] .

\section{MODELS FOR LTTHOSPHERIC EXTENSION}

A local (Airy) compensation mechanism predicts a decrease in elevation over thinned crust that is almost twice the value observed in the Basin and Range near Lake Mead, for the lower bound estimate of $10 \mathrm{~km}$ of Basin and Range crustal thinning. The predicted elevation change $\Delta e$ can be written $\Delta e=-\Delta h\left(\rho_{m}-\rho_{c}\right) / \rho_{m}$, where $\Delta h$ is the crustal thinning and $\rho_{m}$ and $\rho_{c}$ are mantle and crustal densities, respectively. For $\Delta h=10 \mathrm{~km}, \rho_{m}=3300 \mathrm{~kg} / \mathrm{m}^{3}$, and $\rho_{c}=2700 \mathrm{~kg} / \mathrm{m}^{3}$, this model predicts $\Delta e=1800 \mathrm{~m}$, as 


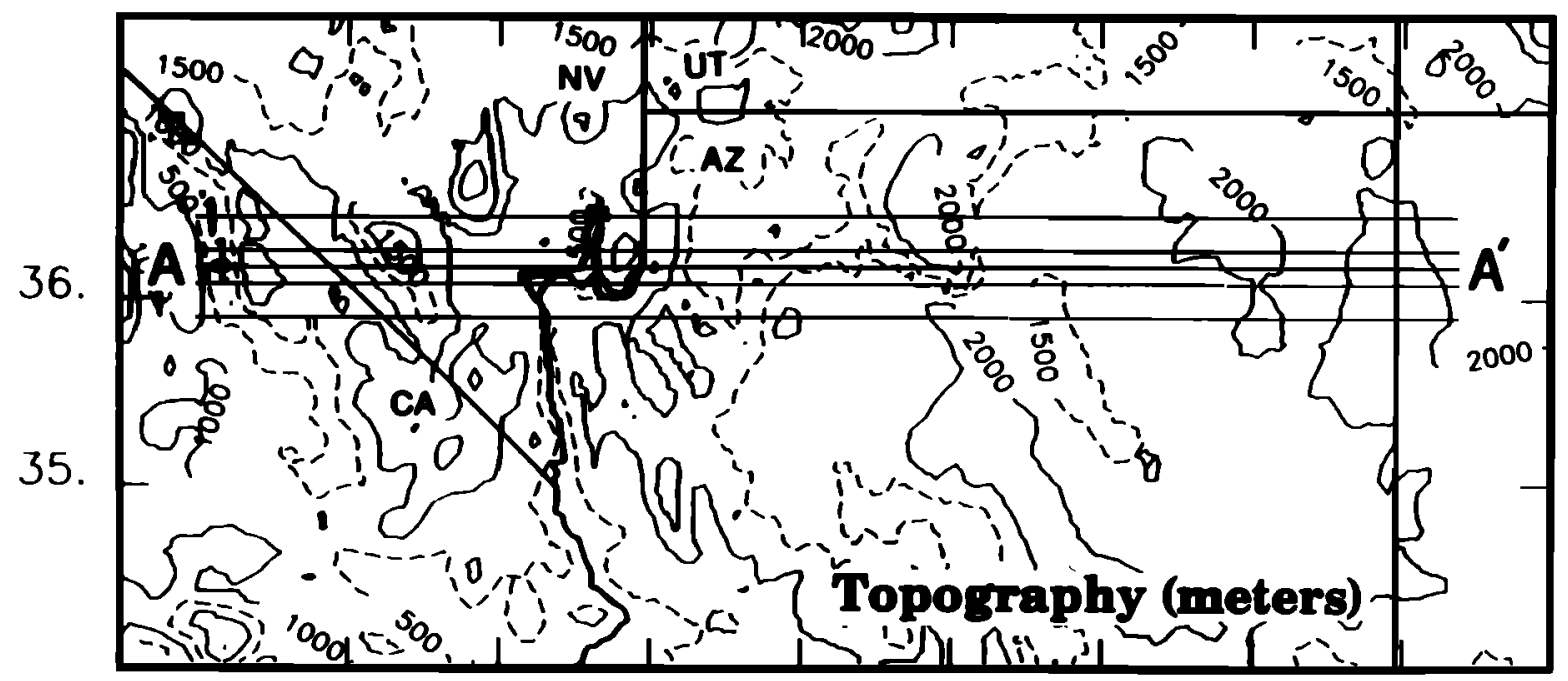

$$
\text { -116. }-115 .-114 .-113 .-112 .-111 .-110 .-109 .
$$

Fig. 3a. Topographic map of Lake Mead area and westem Colorado Plateau. Thick lines mark state boundaries and the shore of Lake Mead. Thin straight lines show the location of topography profiles in Figure 4. Data taken from the NOAA TGP-0030 30' topography data set.

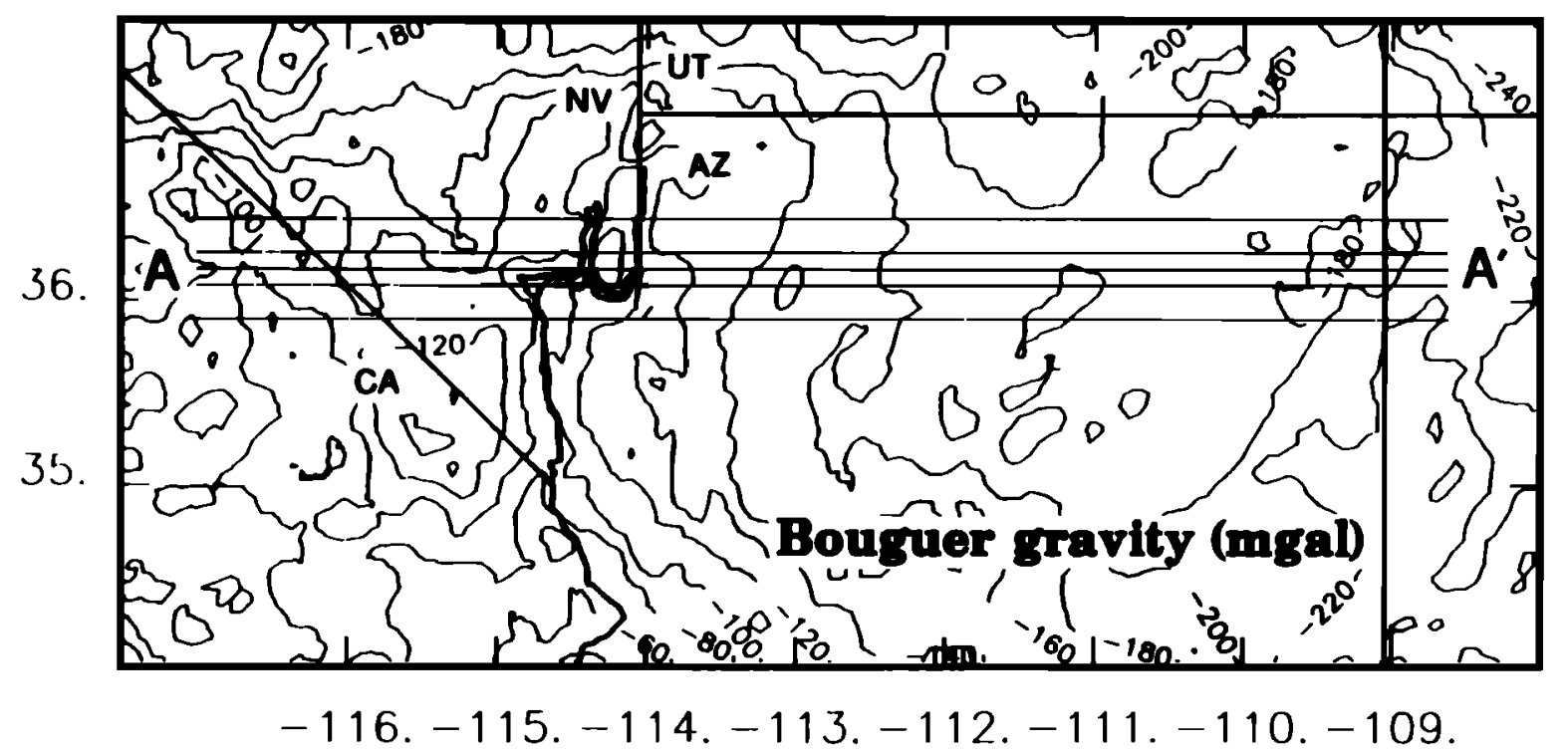

Fig. 3b. Bouguer gravity anomalies in Lake Mead area and westem Colorado Plateau. Thick curves mark state boundaries and the shore of Lake Mead. Thin straight lines show the location of gravity profiles in Figure 4.

compared with the observed 1000 -m topographic step observed across the transition zone.

The simple uniform lithospheric extension model of McKenzie [1978], on the other hand, can predict the difference in topography between unextended and extended regions for $10 \mathrm{~km}$ of thinning of crust initially $\mathbf{4 0} \mathrm{km}$ thick. This model assumes that the temperature at the base of the lithospheric plate remains constant as the mantle and crust extend and thin. The change in elevation $\Delta E$ in lithosphere extending uniformly by a factor $\beta$ can be written

$$
\Delta e=-h_{c} \frac{\left(\rho_{m}-\rho_{\partial}\right)}{\rho_{m}}\left(1-\frac{1}{\beta}\right)+\frac{\rho_{m} \alpha T_{m} y}{2 \rho_{c}}\left(1-\frac{1}{\beta}\right)
$$

[McKenzie, 1978] where $h_{c}$ is the preextensional crustal thickness, $\rho_{m}$ and $\rho_{c}$ are as defined above, $\alpha$ is the coefficient of thermal expansion, $T_{m}$ is the temperature at the base of the mantle, and $l$ is the preextensional thickness of the lithosphere. For extension corresponding to an extension factor of $\beta=1.33(10 \mathrm{~km}$ of thinning of crust initially $40 \mathrm{~km}$ thick), setting $\rho_{m}=3300 \mathrm{~kg} / \mathrm{m}^{3}, \rho_{c}=2700$ $\mathrm{kg} / \mathrm{m}^{3}, \alpha=3 \times 10^{-5}{ }^{\circ} \mathrm{C}-1, T_{m}=1350^{\circ} \mathrm{C}$, and $l=125 \mathrm{~km}$, equation (1) predicts that $\Delta e=-1 \mathrm{~km}$. This model yields a fit to the gravity data which is not as good as that of the Airy model, but does roughly predict the change in gravity anomalies across the transition zone (Figure $5 b$ ).

The uniform extension model fails, however, to predict both the topography and gravity data for the extension estimates corresponding to the $\beta$ values of 1.7 or more estimated by Wernicke et al. [1988]. For an extension factor $\beta=2$, corresponding to $20 \mathrm{~km}$ of thinning of crust initially $40 \mathrm{~km}$ thick, and other lithospheric parameters equal to the values in the 

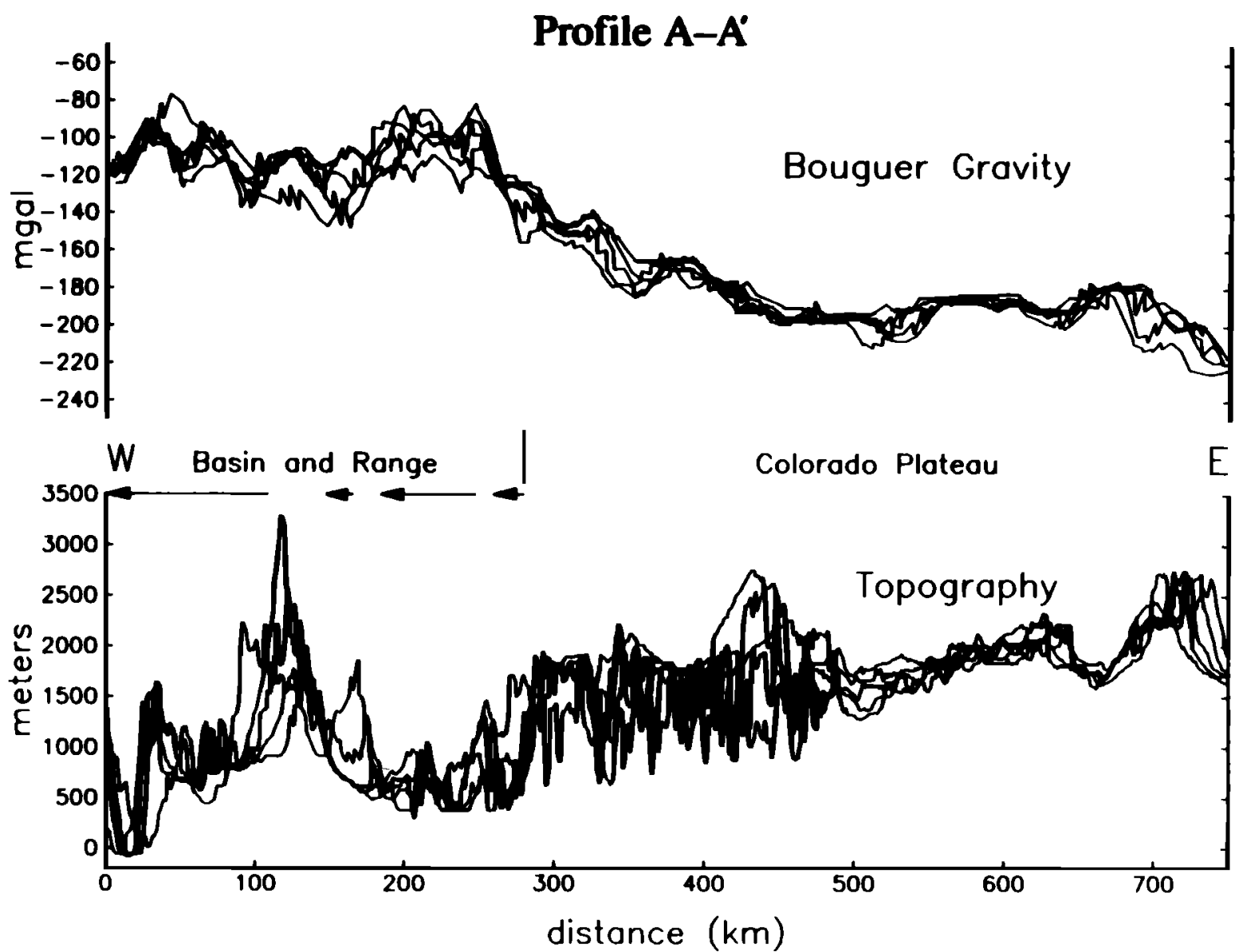

Fig. 4. Bouguer gravity anomalies and topography perpendicular to the strike of the Basin and Range-Colorado Plateau transition. Profile locations shown in Figure 3. Arrows mark the location and amount of extension across the eastem Basin and Range estimated by Wernicke et al. [1988].

preceding example, this model predicts a decrease in elevation over the eastern Basin and Range of approximately $2 \mathrm{~km}$, or twice that observed. Gravity anomalies associated with extension by a factor of two also misfit the observed values (Figure $5 b$ ).

To explain elevations across Lake Mead transition zone, the uniform extension model also requires that the transition in mantle temperatures that result from lithospheric thinning coincides exactly with, and occurs as abruptly as, the transition in crustal thickness. This appears unreasonable over the $50-\mathrm{km}$ wide Lake Mead transition zone, where the topographic elevation and Cenozoic volcanism point to elevated temperatures beneath the unextended Colorado Plateau as well as beneath the Basin and Range (see discussion above). Data in the north central Colorado Plateau also show high heat flow near the edges of the plateau, suggestive of a gradual transition in thermal regimes [Bodell and Chapman, 1982].

Several different mechanisms have been proposed to explain the extension estimates and the topography and gravity data by predicting a difference between whole crustal thinning and the crustal thinning estimated from surface extension. These include (1) initially thicker crust in extended areas, (2) crustal thinning in the hanging wall of large scale low-angle normal shear zones, (3) crustal underplating, and (4) ductile flow in the lower crust. These processes will thin the crust in the unextended region or thicken the crust in the extending region prior to, during, or subsequent to the extension process.

The first mechanism, that presently extended regions correspond to areas of unusually large crustal thickness prior to the onset of extension, has been proposed by several authors [e.g., Coney and Harms, 1984; Mayer, 1986; Holt et al., 1986; Sonder et al., 1987; Dewey, 1988]. Subsequent extension may return the crust in these regions to an "average" crustal thickness. This process appears unlikely in the Lake Mead area, where evidence discussed above points to a relatively uniform preextensional crustal thickness.

The second mechanism invokes large-scale low-angle normal faulting, which will tend to smooth out an abrupt transition in crustal thickness between extended and unextended regions. By this mechanism, simple shear on detachment surfaces is relayed into shear of the lower crust, drawing lower crust out from beneath unextended blocks and into extended regions. This may occur only if the detachment faults or shear zones dip beneath the unextended area [Wernicke, 1985]. This process may be active along other parts of the eastern boundary of the Basin and Range province where breakaway faults dip to the east but is not viable at the latiude of Lake Mead, where the breakaway fault dips westward away from the Colorado Plateau.

The third mechanism, crustal underplating, predicts that addition of mantle-derived material at the base of the crust can occur as a result of melt generation associated with ascent to crustal depths of mantle-derived basaltic magma [e.g., Furlong and Fountain, 1986]. Several authors have suggested that this process may be a viable mechanism for crustal replenishment in the Basin and Range [Furlong and Fountain, 1986; Okaya and Thompson, 1986; Thompson and McCarthy, 1986; Gans, 1987]. We feel that the 
underplating model is a somewhat ad hoc explanation for the apparent discrepancy between crustal extension and crustal thinning because the mantle-derived additions to the crust must coincide precisely with regions of crustal extension.

The underplating mechanism may also not be capable of adding an amount of crustal material sufficient to explain the observations near Lake Mead. Unless there is an exceptionally large and abrupt discontinuity in mantle densities across the transition zone, the underplating mechanism must add of the order of 5-10 km or more of material to the base of the extended crust. To add 5-10 km to the base of the crust at $30-40 \mathrm{~km}$ depth, however, requires an extremely warm plume capable of efficient segregation of melts generated at depths to $100 \mathrm{~km}$ or more [Furlong and Fountain, 1986].

The fourth mechanism, redistribution of ductile lower crustal material driven by lateral pressure gradients due to variations in the thickness of the overlying upper crust, will also tend to smooth out variations in total crustal thickness. Ductile crustal flow has previously been proposed to explain the relative uniformity of topography over regions of variable extension [Wernicke, 1985;
McKenzie, 1988; Spencer and Reynolds, 1989] and the lack of subsidence over denuded core complexes [Block and Royden, 1990]. McCarthy and Thompson [1988] interpret the large number of lower crustal reflectors in extensional provinces in the western United States as possible evidence for ductile strain (or intrusive layering) in the lower crust. Influx of crustal material beneath uplifted regions is also assumed in the isostatic response of the crust in Buck's [1988] model for the generation of low angle normal faults in metamorphic core complexes and in the model of Wernicke and Axen [1988] for the uplift of footwalls of normal faults. In the following sections we examine the conditions under which such flow in the crust could add $5-10 \mathrm{~km}$ to the thickness of extended crust observed at Lake Mead.

\section{DUCTIE FLOW MODELS}

\section{Rheological Justification}

Justification for modeling the effects of ductile flow at lower crustal depths comes from laboratory experiments [e.g., Goetze

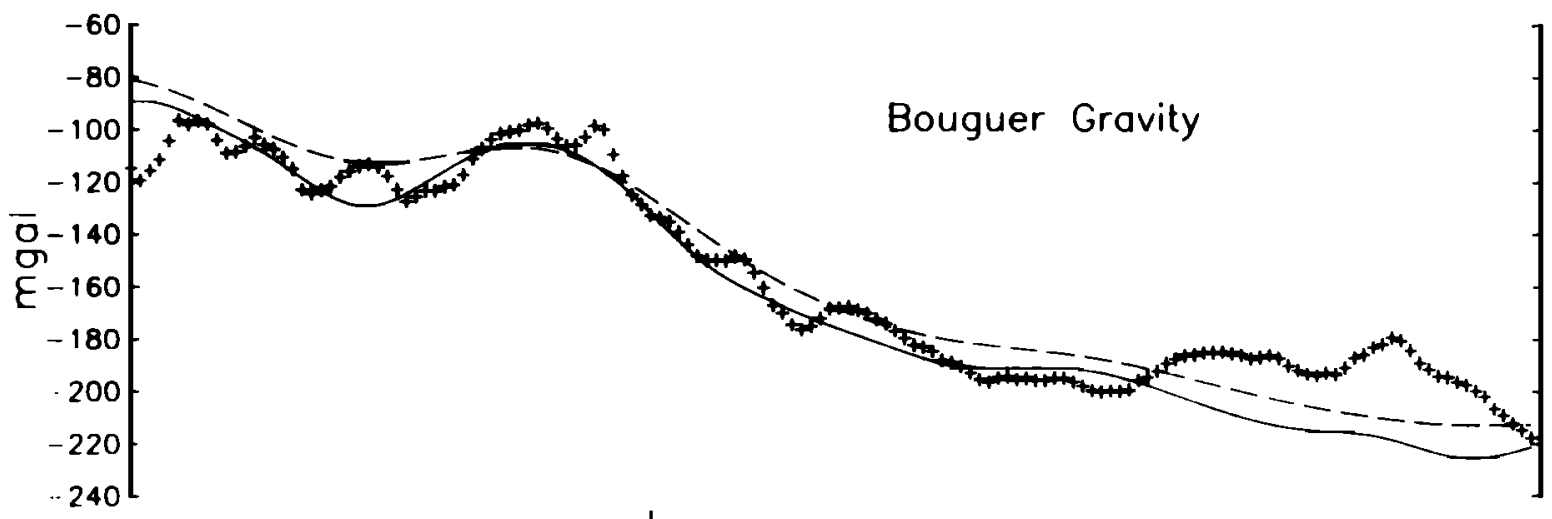

$B$ and $R$

$\mathrm{CP}$

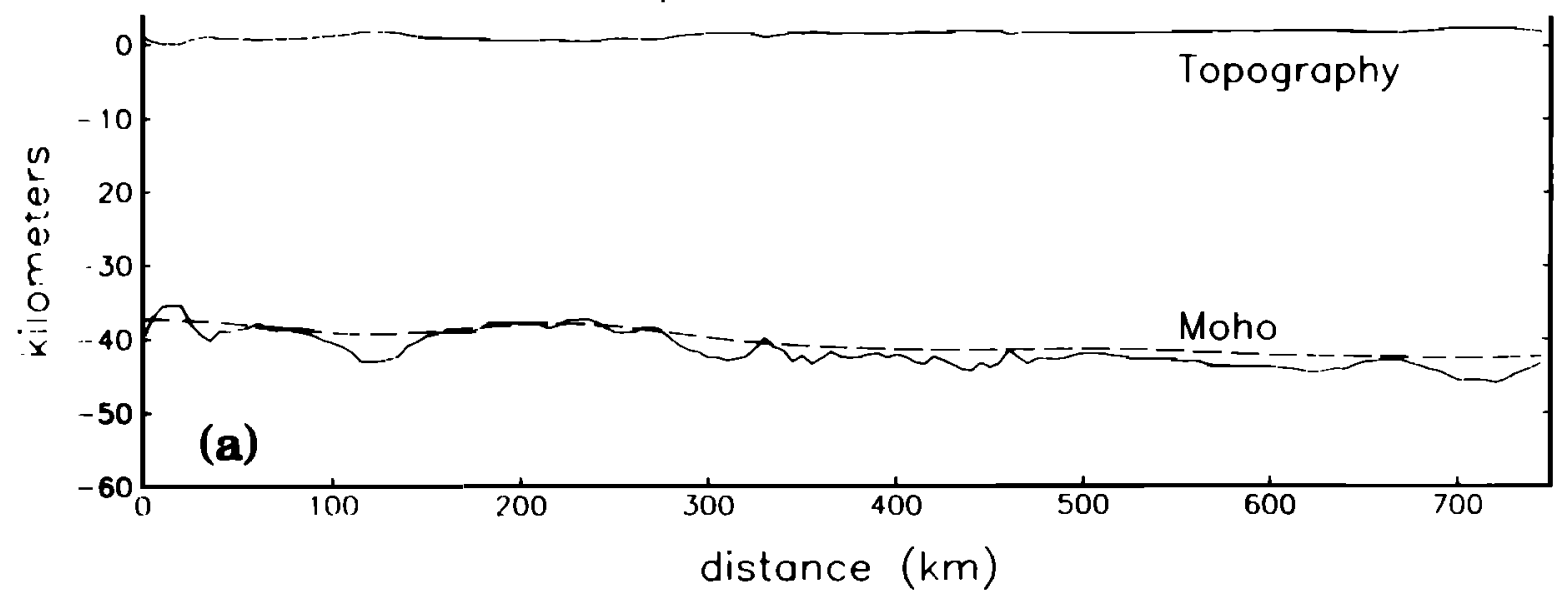

Fig. 5. Bouguer gravity anomalies predicted by simple compensation models. Topography data used in modeling are averaged from the five profiles of Figure 4. Crosses mark observed Bouguer gravity anomalies similarly averaged from the profiles of Figure 4. Shon vertical line between upper and lower plots marks location of transition zone. (a) Solid curve shows local (Airy) compentation of topography by deflections of the Moho. Dashed curve shows compensation at Moho assuming a flexural rigidity of $1022 \mathrm{~N} \mathrm{~m}$. (b) Bouguer gravity anomalies and Moho depths corresponding to uniform stretching of the lithosphere west of the transition zone according to the model of McKenzie [1978]. Solid curves indicate values associaled with extension by a factor $\beta=1.33$, resulting in $10 \mathrm{~km}$ of crustal thinning of crust initially $40 \mathrm{~km}$ thick. Dashed curves show values predicted from extension by a factor of 2 with $20 \mathrm{~km}$ of crustal thinning. Bouguer gravity anomalies are calculated assuming that the lithosphere in the extended region has thimned uniformly, maintaining a linear temperature gradient between the surface and a temperature of $1350^{\circ} \mathrm{C}$ at the base of the lithospheric plate. The unextended thickness of the lithospheric plate is set to $125 \mathrm{~km}$. Deflections of the Moho maintain local (Airy) isostasy. To best fit the observed gravity data $-200 \mathrm{mGal}$ were added to the gravity predicted by the model for $\beta=1.33$ (solid curves) and 250 $\mathrm{mGal}$ were added to the gravity predicted by the $\beta=2$ (dashed curves) model. 

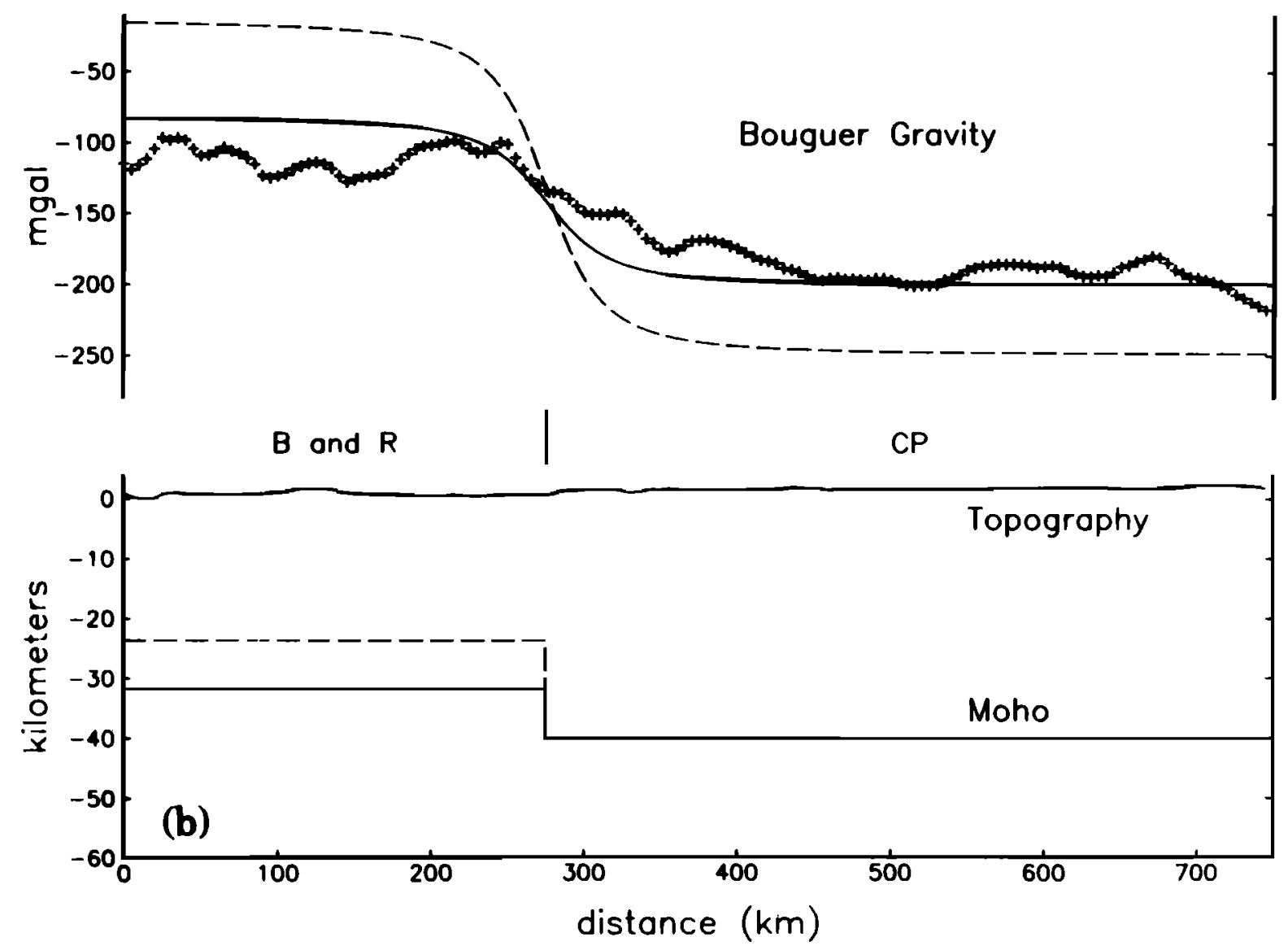

Fig. 5. (continued)

and Evans, 1979; Brace and Kohlstedt, 1980; Kirby, 1983] and geological and seismic observations [e.g., Smith and Bruhn, 1984; McCarthy and Thompson, 1988] which suggest that crustal materials may deform ductilely under the pressure and temperature conditions found in the lower crust. Both laboratory and field observations suggest that the lower crust may be a weak layer bounded above and below by stronger layers. Figure $6 a$ illustrates the maximum deviatoric stresses predicted for a continental lithosphere with a temperature gradient of $10^{\circ}-20^{\circ} \mathrm{C} / \mathrm{km}$ in the upper crust and approximately $10^{\circ} \mathrm{C} / \mathrm{km}$ in the lower crust and mantle, for a strain rate of $10^{-15} \mathrm{~s}^{-1}$. The weak region at lower crustal depths where maximum deviatoric stresses are small is presumed to be bounded above by a transition from brittle to ductile behavior and from below by a compositional transition at the Moho. Both the nature and depth of these transitions, however, are highly dependent on the geotherm, strain rates, and compositions assumed and are in general poorly known. Carter and Tsenn [1987] have shown that the depth of a brittle-ductile transition may begin at virtually any depth greater than $10 \mathrm{~km}$, depending on the composition, temperature, and strain rate within the crust. Under certain conditions more than one weak ductile layer may exist as well (Figure 6b [Smith and Bruhn, 1984]).

In the following sections we discuss three models for lower crustal ductile flow that give progressively better approximations to the lithospheric rheology assumed for and the conditions observed at the Lake Mead transition zone: (1) an analytical approximation to two-dimensional linear viscous flow in a channel; (2) finite element modeling of linear viscous flow under geometric conditions more closely approximating those at Lake Mead; and (3) modeling of flow governed by power law creep mechanisms.

\section{Channel Flow Approximation}

Figure $7 a$ illustrates the highly simplified two-dimensional model of lithospheric structure used to examine the conditions under which ductile flow of lower crustal material can significantly thicken the lower crust beneath regions of extended upper crust. Ductile flow is assumed to occur within a channel with distinct boundaries. The upper crust overlying the ductile channel is assumed to have no flexural rigidity and acts as a passive load on the ductile layer. In this paper we use the term upper crust to describe all material above the ductile channel. We prescribe thinning of the upper crust as a boundary condition on the underlying ductile flow. In the first series of models the lower boundary of the ductile channel is assumed to be rigid and flat, ignoring deflections associated with deformation in deeper layers. We also assume initially that there is no difference in density between material forming the upper crust and the material in the ductile channel, and that the ductile layer behaves as a linear (Newtonian) viscous fluid.

In this model, lateral variations in the mass of upper crustal material induce lateral variations in pressure in the underlying fluid layer. Flow in response to these pressure gradients carries material away from regions of high pressure corresponding to areas with large upper crustal thicknesses toward regions of lower pressure where upper crust is thinner. Pressure gradients are reduced as flow in the fluid layer increases the weight of fluid material in 

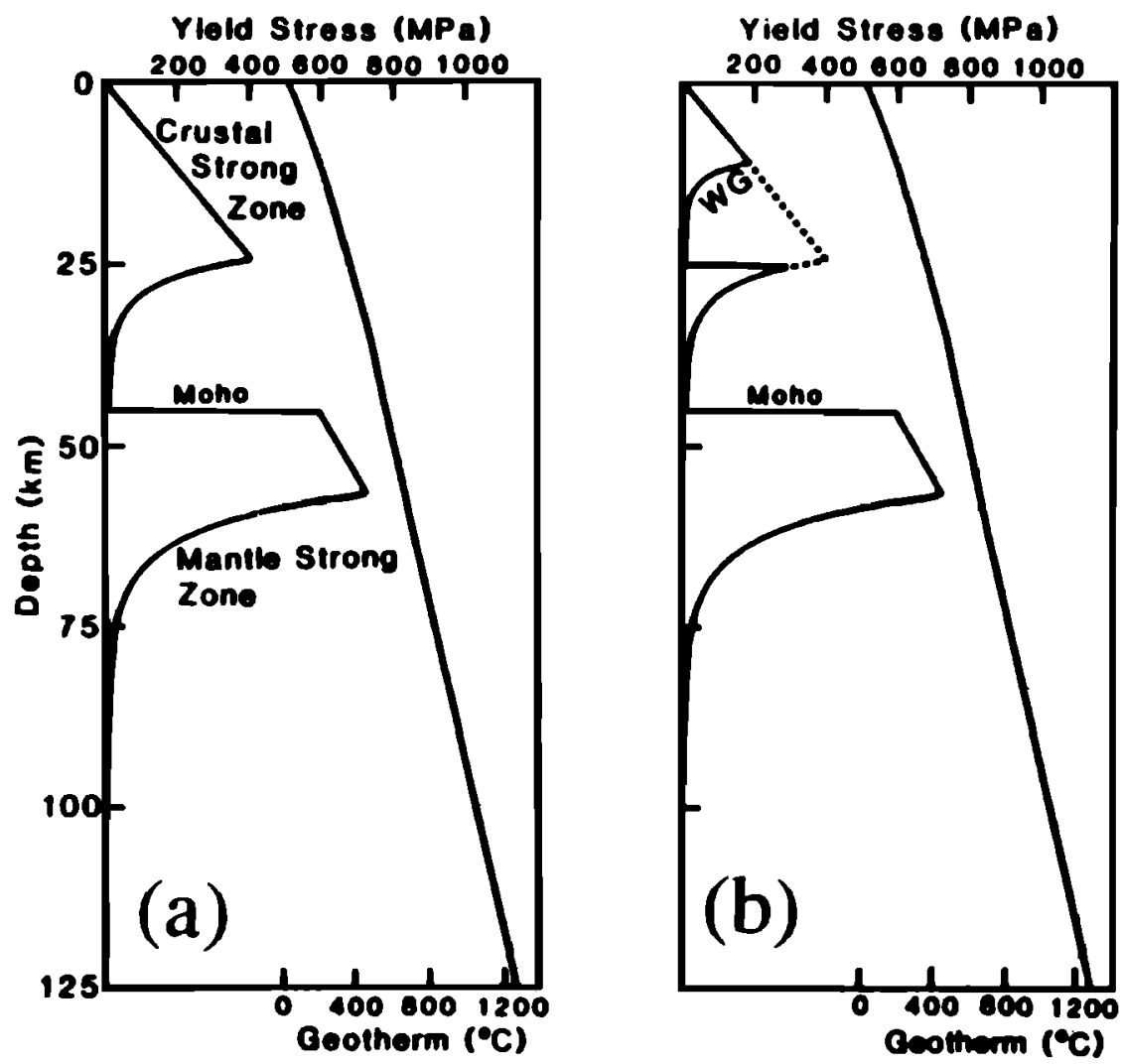

Fig. 6. Maximum deviatoric stress that can be maintained in continental lithosphere, assuming an olivine theology for the mantle and strain rate of $10^{-15} \mathrm{~s}^{-1}$. Figure modified from Dunbar and Sawyer [1989]. Regions of linearly increasing yield stress with depth deform according to Byerlee's law for britule deformation. Ductile deformation occurs in the regions where yield stress decreases exponentially with depth. (a) Quartz diorite crustal rheology. (b) Wet granite rheology in the upper crust introduces a second layer of ductile deformation and substantially weakens the crust relative to model in Figure $6 a$.

regions of initially lower pressure, increasing the pressure in these regions.

An approximate upper bound on the viscosity required for flow in a channel to redistribute lower crustal material can be derived as follows. We can approximate such flow with an analytical solution for two-dimensional linear viscous flow in a channel. The flow rate $q$ of a fluid with Newtonian viscosity $\mu$ through a channel with thickness $D$ under a lateral pressure gradient $d p / d x$ can be written

$$
q=\frac{D^{3}}{12 \mu} \frac{d p}{d x}
$$

where $x$ is the horizontal coordinate [see e.g., Turcotte and Schubert, 1982]. This approximation assumes that lateral variations in the thickness of the ductile layer are gentle, such that $d D(x) / d x$ $\ll 1$. It further assumes that no lateral flow occurs at the Moho. If instead the Moho is taken to be a stress-free boundary, then

$$
q=\frac{D^{3}}{3 \mu} \frac{d p}{d x}
$$

Horizontal pressure gradients in the ductile channel are produced by differences in the weight of the overlying crust. We assume that the initial pressure gradient can be approximated by the difference between pressures associated with unextended upper crust and with upper crust thinned by an amount $\Delta h$ and can be expressed as

$$
\frac{d p}{d x} \approx \frac{\rho_{c} g \Delta h}{L / 2}
$$

where $\rho_{c}$ is the density of the crust and $g$ is the gravitational acceleration. $L$ is the horizontal length scale, or distance required for flow between unextended and thinned regions. This assumes the Moho remains at constant depth and there is no compensation for crustal thinning. If we consider Airy compensation, then

$$
\frac{d p}{d x} \approx \frac{\left(\rho_{m}-\rho_{\partial}\right) \rho_{c} g \Delta h}{\rho_{m} L / 2},
$$

where $\rho_{m}$ is the density of the mantle. Assuming that upper and lower crustal densities are equal, flow is "complete" in the sense that all lateral variations in total crustal thickness are eliminated when a volume of lower crustal material of thickness $\Delta h / 2$ (equivalent to one half the volume of upper crustal material removed during thinning) has moved a distance $L / 2$ from the unthinned to the thinned region. If we require that this volume of crustal material must flow during the time interval $\Delta t$, the fluid flow rate $q$ becomes

$$
q \approx \frac{\Delta h L}{4 \Delta t}
$$

Equating the flow rates of equations (4) and (2) and assuming that the pressure gradients over the time $\Delta t$ may be represented by an 


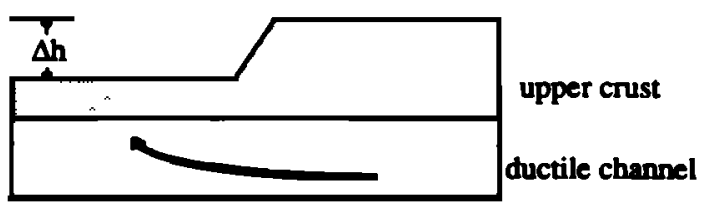

(a)

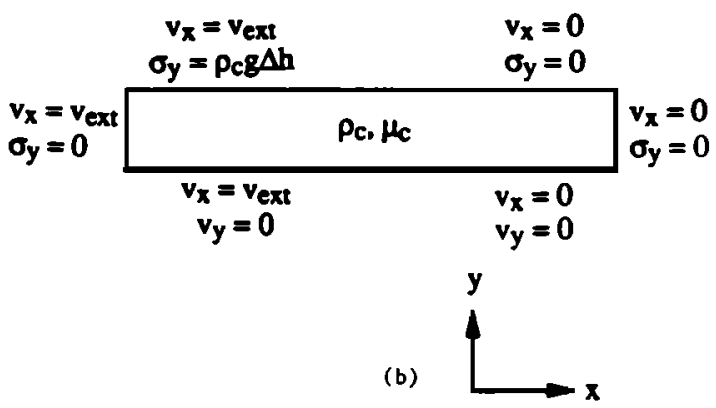

Fig. 7. (a) Schematic representation of ductile flow in response to upper crustal thinning. (b) Boundary conditions on finite element models for a ductile channel with a fixed lower boundary.

average pressure that is equal to half the initial pressure in equation (3), we solve for the viscosity $\mu$ required for "complete" flow:

$$
\mu \approx \frac{D^{3} \rho_{c} g \Delta t}{3 L^{2}}
$$

The viscosity required for fluid flow to be effective at reducing lateral variations in total crustal thickness thus depends most strongly on the channel thickness $D$ and the length scale $L$. Low viscosities are required to maintain flow of material in narrow channels and across longer distances. The viscosity is independent of the magnitude of the crustal thinning $\Delta h$ when variations in the channel thickness as flow occurs are small compared to $D$.

Setting values appropriate for the minimum crustal thinning west of the Lake Mead transition zone: $\rho_{c}=2600 \mathrm{~kg} / \mathrm{m}^{3}, g=10 \mathrm{~m} / \mathrm{s}^{2}, \Delta t$ $=10 \mathrm{~m} . y$., we find that fluid channel flow keeps pace with upper crustal thinning over the length scale of the eastern Basin and Range and western Colorado Plateau $(L \approx 700 \mathrm{~km}$ ) for viscosities less than $1 \times 10^{20} \mathrm{~Pa} \mathrm{~s}$ and $5 \times 10^{18} \mathrm{~Pa}$ for channels with thicknesses of 25 and $10 \mathrm{~km}$, respectively. For flow of narrower lateral extent (for example, $L=150 \mathrm{~km}$ ), viscosities less than $2 \times 10^{21} \mathrm{~Pa} \cdot \mathrm{s}$ and $1 \times$ $10^{20} \mathrm{~Pa} \mathrm{~s}$ for 25 and $10 \mathrm{~km}$ thick channels, respectively, are required. Viscosities twice as large correspond to flow that reduccs the lateral variations in crustal thickness by a factor of two over the same time period (for example, producing $5 \mathrm{~km}$ of net crustal thinning in a region that has undergone $10 \mathrm{~km}$ of upper crustal thinning). These upper bounds for two-dimensional flow are conservative since we have neglected the effects of thinning of the channel as lower crust material flows away from unextended regions. The bounds are reduced by $15 \%$ if we include Airy compensation and flow at the Moho. Consideration of threedimensional flow may raise these bounds, as discussed further below.

\section{Finite Element Models of Linear Viscous Flow}

Finite element modeling was used to examine the pattern of linear viscous flow and the viscosities that could produce $5-10 \mathrm{~km}$ of thickening in a ductile channel under conditions more closely approximating those in the Lake Mead area. A description of the method used is contained in the appendix. Figure $7 b$ illustrates the boundary conditions imposed on the finite element grid in order to simulate the effect of upper crustal thinning on ductile lower crustal and mantle layers. Thinning of the upper crust is imposed over the left side of the grid (the "Basin and Range") and is described by a vertical stress $\sigma_{y}=\rho_{c} g \Delta h$ specified on the left side of the upper boundary. A progressive increase in upper crustal thinning through time is modeled with an increase in the imposed upward stress through time. The boundary conditions on the sides of the grid are stress free in the vertical direction, with zero horizontal velocity on the right (unextended) side, and a specified horizontal velocity on the left (extending) side. The first models discussed below (Figures 8-15) assume a single lower crustal channel with a lower boundary with zero vertical velocity, such that the boundary is fixed, as in Figure $7 b$. These simple one-layer models thus neglect the effects of an underlying mantle fluid layer and are equivalent to a rigid (infinite flexural rigidity) mantle.

Figure $8 a$ illustrates an example of the initial grid used in the single-layer models, in this case for a channel $25 \mathrm{~km}$ thick. For thinner channels the vertical dimension of the elements was simply scaled down, such that the ductile layer was modeled in each case with the same number of elements. Computation of the deformation of the viscous layer through time is described in the Appendix. An example of the state of the finite element grid for the 25-km-thick channel after $10 \mathrm{~m} . y$. of flow in response to $10 \mathrm{~km}$ of upper crustal thinning over the left side of the grid is shown in Figure $8 b$.

In a set of models (Figures 9-11) we assume that horizontal velocities on the upper and lower boundaries of the extending region (left side of grid) are zero. This assumption represents a simple shear type of extension or unroofing of the upper crust in which the ductile channel is not actively extending as the upper crust thins. Boundary conditions approximating the Lake Mead setting are then imposed. We assume $10 \mathrm{~km}$ of crustal thinning has occurred over the last $10 \mathrm{~m}$.y over one half of a $700-\mathrm{km}$-wide region. For ease of computation, stress boundary conditions corresponding to upper crustal thinning in $1 \mathrm{~km}$ increments every $1 \mathrm{~m} . \mathrm{y}$. were imposed. The width of a transition zone where stresses vary linearly from "unextended" to "thinning" values was set to $20 \mathrm{~km}$.

An example of the pattern of lateral flow between the regions of unextended and thinned upper crust in such a ductile channel is illustrated in Figure 9, where we have assumed a fluid viscosity of $10^{20} \mathrm{~Pa} \mathrm{~s}$ in a channel $25 \mathrm{~km}$ thick. Flow is still concentrated near the transition zone after $2 \mathrm{~m} . \mathrm{y}$. $(2 \mathrm{~km})$ of thinning, but, by $8 \mathrm{~m} . \mathrm{y}$. (and $8 \mathrm{~km}$ of thinning), horizontal flow is well developed throughout the channel.

In modeling the observations in the Lake Mead area we are interested in finding the range of conditions under which ductile flow will produce a variation in crustal thickness between the Basin and Range and the Colorado Plateau that is $5 \mathrm{~km}$ or less, given 10 $\mathrm{km}$ of upper crustal thinning in the Basin and Range over the last 10 m.y. Crustal thickness variations between 0 and $5 \mathrm{~km}$ may be compatible with the topography and gravity data if lateral variations in elevations are compensated by lateral density variations within the crust. This is discussed further below. Figure 10 illustrates the changes in the thickness of the ductile channel and the associated change in total crustal thickness for the flow conditions shown in Figure 9 and for flow of viscosity $10^{19} \mathrm{~Pa}$ s under identical boundary conditions. After $10 \mathrm{~m} . \mathrm{y} ., 10 \mathrm{~km}$ of upper crustal thinning, and underlying channel flow, the discrepancy in total crustal thickness between the unextended and thinned regions is 


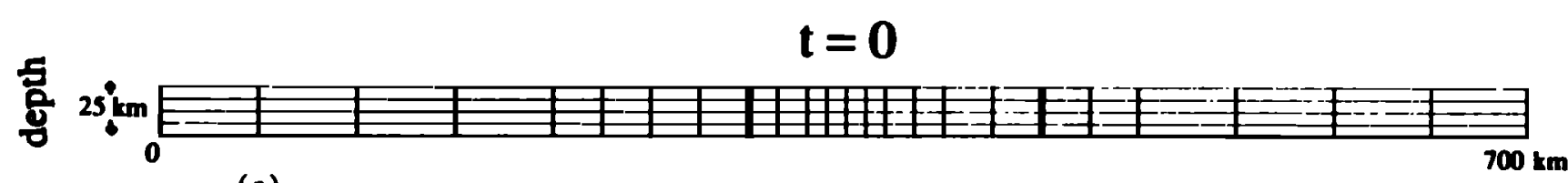

(a)

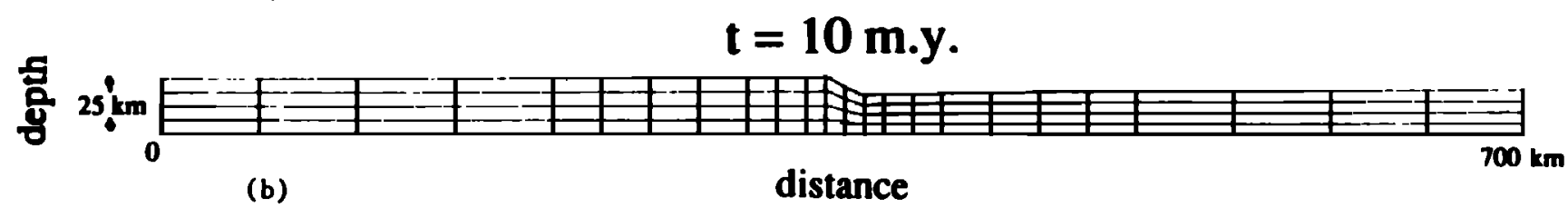

Fig. 8. Finite element mesh used for modeling flow in ductile channel with fixed lower boundary. Thick vertical lines show side boundaries of grid used to model flow over a $150 \mathrm{~km}$ length scalc. Lines connect nodes of nine-node elements. (a) Mesh for 25$\mathrm{km}$ thick channel model prior to deformation. (b) Sample of mesh after $10 \mathrm{~m} . \mathrm{y}$. of flow at viscosity $10^{20} \mathrm{~Pa} \mathrm{~s}$ in response to 1 $\mathrm{km} / \mathrm{m} . \mathrm{y}$. upper crustal thinning.

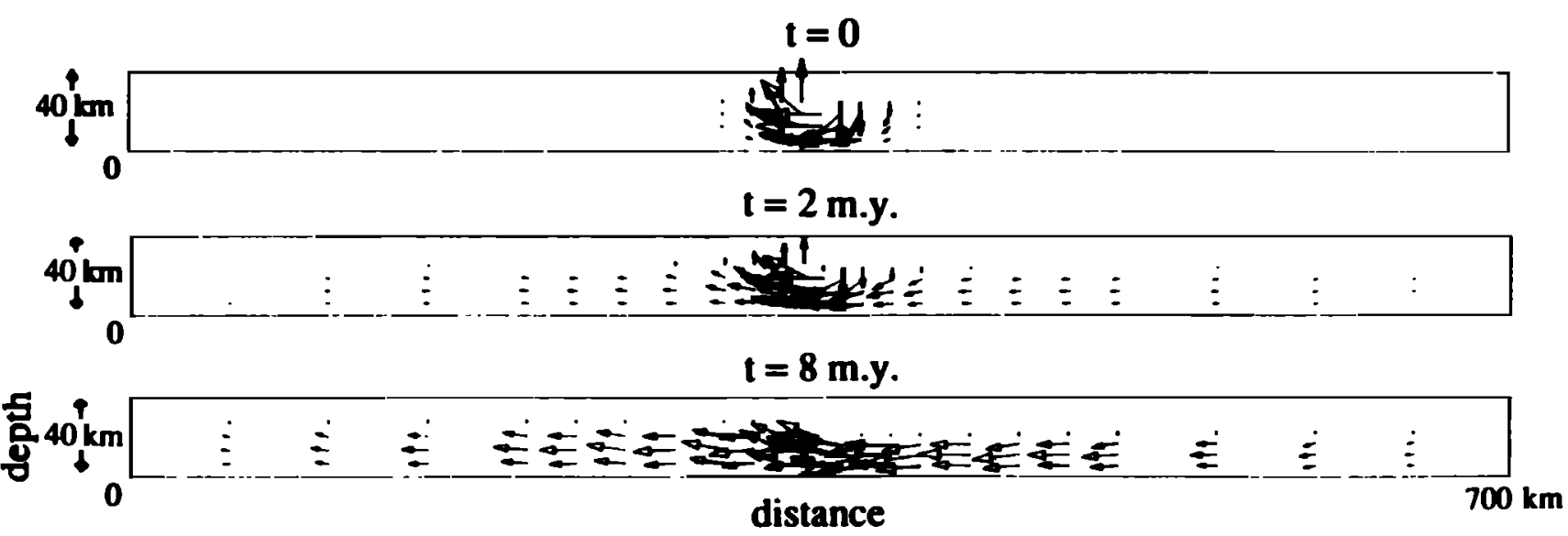

Fig. 9. Velocity vectors for flow in a 700-km long channel initially $25 \mathrm{~km}$ thick with viscosity $10^{20} \mathrm{~Pa} \mathrm{~s}$ at times $0,2 \mathrm{~m} . \mathrm{y}$. , and 8 m.y. assuming upper crustal thinning over the left side of the mesh at a rate of $1 \mathrm{~km} / \mathrm{m} . \mathrm{y}$.

approximately $5 \mathrm{~km}$ for $10^{20} \mathrm{~Pa}$ s flow and virtually zero for $10^{19}$ $\mathrm{Pa} s$ flow. Thus both models are defined as successful in that they satisfy the above criteria for total crustal thickness variations across the Lake Mead transition zone.

We note here that the apparent $-100-\mathrm{m}$ jaggedness in the elevation in the upper boundary of the ductile channel (and hence in the upper crustal surface) does not correspond to a real physical process but is an artifact of the finite element technique, grid spacing, and boundary conditions used in this study. This jaggedness serves as an indication of the resolution of this model for displacements near the transition zone. See the appendix for further discussion.

Finite element modeling under the boundary conditions above indicates that "acceptable" fluid viscosities, those that reduce crustal thickness variations across the transition zone to $5 \mathrm{~km}$ or less, are highly dependent on the channel thickness assumed. The relationship between the upper limit on acceptable viscosity and the channel thickness is shown in Figure 11. The upper limiting viscosities range from somewhat more than $10^{19} \mathrm{~Pa}$ for flow in a 25-km thick channel to less than $10^{17} \mathrm{~Pa}$ s for a 5-km-thick channel.

Figure 11 indicates that the analytical approximation to the viscosity that yields zero variations in total crustal thickness (dashed curve) is in reasonably good agreement with the results of the finite element modeling for a channel thickness greater than $10 \mathrm{~km}$. For thicker channels the flow features neglected in the analytical approximation, such as flow near the transition zone, pinching of the channel as flow is driven from the unextended region, and imposed side boundary conditions, are shown to be second order effects compared to the values of the initial chamel thickness and the viscosity. For narrower channels, thinning of the channel in the unextended region caused a significant reduction in channel thickness and thereby significantly reduced flow rates. The numerical models for narrower channels thus require lower viscosities than do the analytical solutions.

To model a ductile channel that is itself is actively extending, we modify the boundary conditions so that the horizontal velocities on the upper and lower boundaries of the channel in the extending region (left side of the grid) impose displacements away from the unextended region. Figure 12 shows velocities in such a model for a $25-\mathrm{km}$ thick channel $5 \mathrm{~m}$.y. after the onset of extension and upper crustal thinning. The horizontal velocities imposed on the grid boundaries correspond to extension in the left half of the ductile channel by a factor of 2 over $10 \mathrm{~m} . y$. Lateral flow in the extending region is enhanced relative to the models above with zero horizontal velocity boundary conditions. Because the ductile channel is thinning by extension, the influx of material from the unextended region must be greater than in the models above in order to reduce lateral disparities in total crustal thickness. Thus lower viscosities are required if we assume that material in the ductile channel is actively extending as well as responding to upper crustal thinning. For example, the upper bound on acceptable viscosities for the Lake 

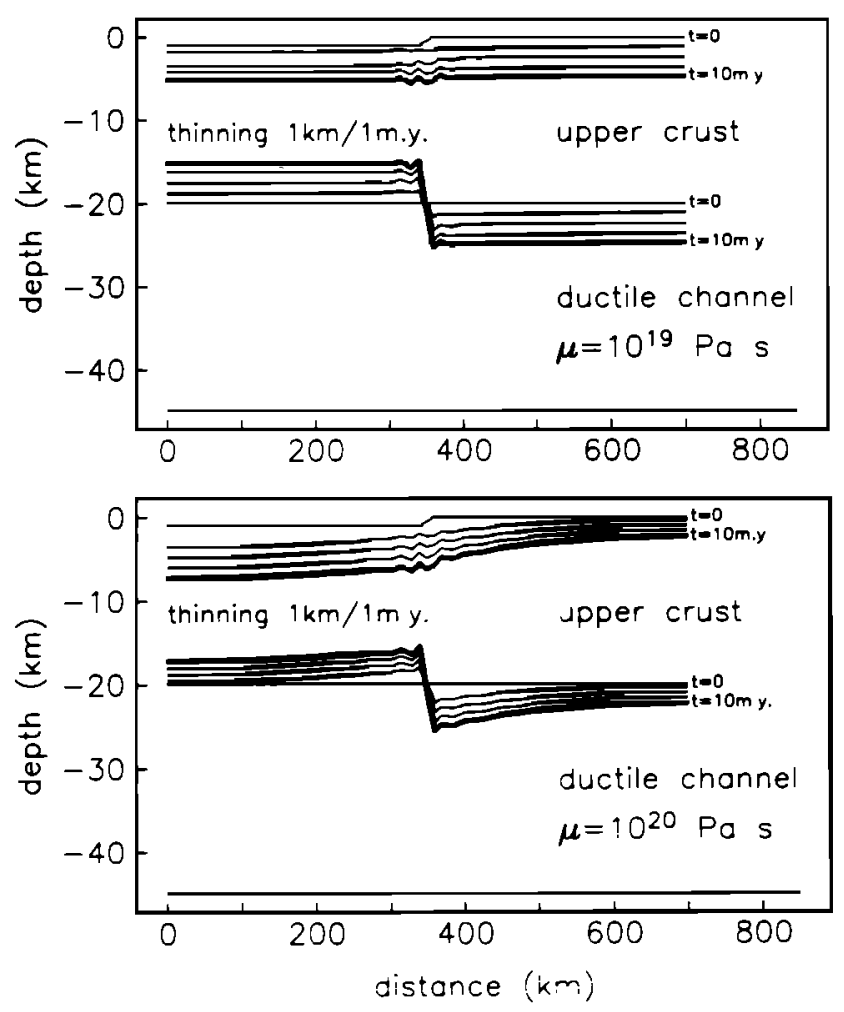

Fig. 10. Variations in total crustal thickness and ductile channel thickness for flow in a channel initially $25 \mathrm{~km}$ thick with a fixed lower boundary. The upper crust has zero flexural rigidity and thins over the left side of the mesh at a rate of $1 \mathrm{~km} / \mathrm{m} . \mathbf{y}$.

Mead geometry is reduced from $10^{20} \mathrm{~Pa} s$ for the simple crustal thinning model to $10^{19} \mathrm{~Pa}$ s for the extending ductile channel model when a $25-\mathrm{km}$ channel thickness is used.

In modeling illustrated in Figure 13 we relax the assumption that the lower boundary of the ductile channel is fixed and assume instead that another fluid layer underlies the ductile channel. We assume that the lower boundary of the ductile channel coincides with the crust-mantle boundary (as in Figure 6) and thus use the terms "lower boundary" and "Moho" interchangeably. Figure 13 shows the grid and boundary conditions of finite element models of a linear viscous mantle underlying the crustal channel. In all models we assumed a $200-\mathrm{km}$-thick mantle layer with a viscosity of $10^{21}$ $\mathrm{Pa} \mathrm{s}$ and found that the Moho is deflected upward beneath the extended areas as the mantle flows. The upward deflection of the Moho introduces a kink into the crustal channel at the transition zone and reduces the lateral pressure gradients in the lower crustal channel. These processes are addressed in more detail in the discussion below. The finite element models show the net effect of the Moho deflections is to reduce the upper limits on acceptable viscosities for the crustal channel by approximately $30 \%$ from the values of the fixed lower boundary models for a $25-\mathbf{k m}$-thick crustal channel and $50 \%$ for a $10-\mathrm{km}$ thick channel. In the $5-\mathrm{km}$ thick channel model, the kink induced in the channel at the transition zone after $2-3 \mathrm{~km}$ of upper crustal thinning is sufficient to produce a constriction of the channel that drastically inhibits flow. Numerical instabilities prevented quantification of the reduction in flow rates as the channel is constricted.

In summary, the most conservative upper bounds on viscosities required for linear viscous flow to produce total crustal thickness variations of $5 \mathrm{~km}$ or less under conditions approximating those observed at Lake Mead (a length scale of $700 \mathrm{~km}$; crustal thinning of $10 \mathrm{~km}$ over $10 \mathrm{~m}$.y.) range from $10^{18} \mathrm{~Pa}$ s to $10^{20} \mathrm{~Pa}$ s for channels $5-25 \mathrm{~km}$ thick (Figure 11). Consideration of the effects of extension in the ductile channel and flow in the mantle may reduce these upper bounds by as much as an order of magnitude.

\section{Modeling of Power Law Flow}

Experimental evidence indicates that lower crustal material flows according to a power law, rather than linear viscous rheology [e.g., Kirby, 1983] and that strain rates $\dot{\varepsilon}$ in the ductile regime can be described by the relation

$$
\dot{\varepsilon}=A\left(\sigma_{1}-\sigma_{3}\right)^{n} \mathrm{e}^{-Q /(R T)}
$$

where $\left(\sigma_{1}-\sigma_{3}\right)$ is the deviatoric stress, $R$ is the universal gas constant, $T$ is the temperature in Kelvin and $A, n$, and $Q$ are experimentally determined constants. An effective viscosity $\mu_{\text {eff }}$ that relates deviatoric stress and strain rate via

$$
\left(\sigma_{1}-\sigma_{3}\right)=2 \mu_{\text {eff }} \dot{\varepsilon}
$$

can be defined for power law flow. This effective viscosity is thus equivalent to a viscosity defined for linear viscous flow. Combining equations (6) and (7), the effective viscosity $\mu_{\text {eff }}$ of the power law stress-strain rate can be written in terms of the strain rate

$$
\mu_{e f f}=\frac{\dot{\varepsilon}^{(1 / n)-1} \mathrm{e}^{\ell(n R T)}}{2 A^{1 / n}}
$$

$$
\text { channel length } 700 \mathrm{~km}
$$

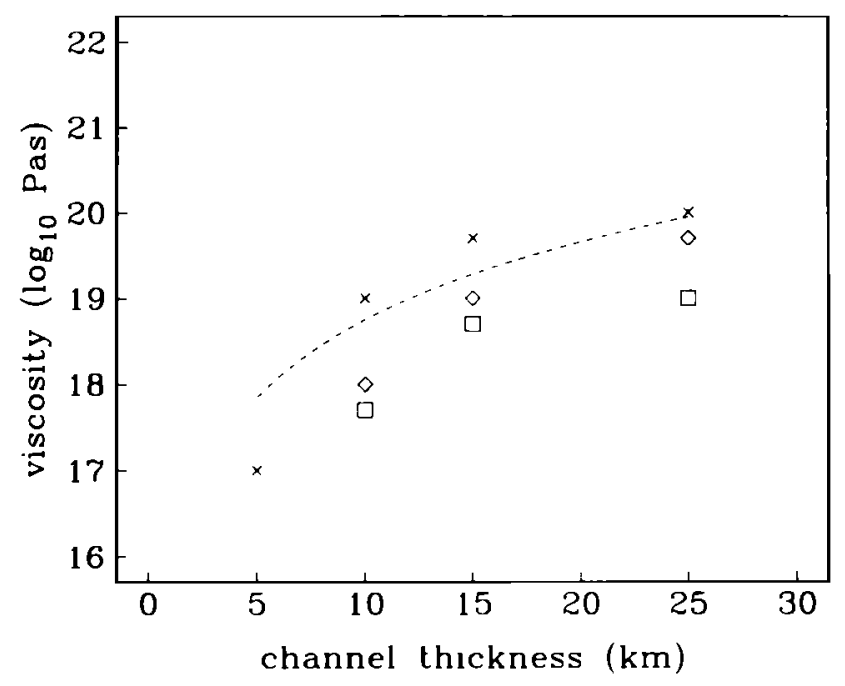

Fig. 11. Compilation of finite element and analytical modeling results for linear viscous flow. Diamonds mark parameters of runs that predicted 5 $\mathrm{km}$ or more of ductile channel thickening beneath the thinned upper crust after $10 \mathrm{~m} . y$. of upper crustal thinning at a rate of $1 \mathrm{~km} / \mathrm{m} . y$. Crosses mark runs that predicted less than $5 \mathrm{~km}$ of ductile channel thickening. Squares mark runs in which total crustal thicknesses are uniform across the transition zone after $10 \mathrm{~m} . y$. Dashed curve shows the viscosities corresponding to "complete" flow (uniform total crustal thickness) computed with equation (5). 
extension by 2 over $10 \mathrm{~m} . \mathrm{y}$.

$$
\mu=10^{19} \mathrm{~Pa} \cdot \mathrm{s}
$$
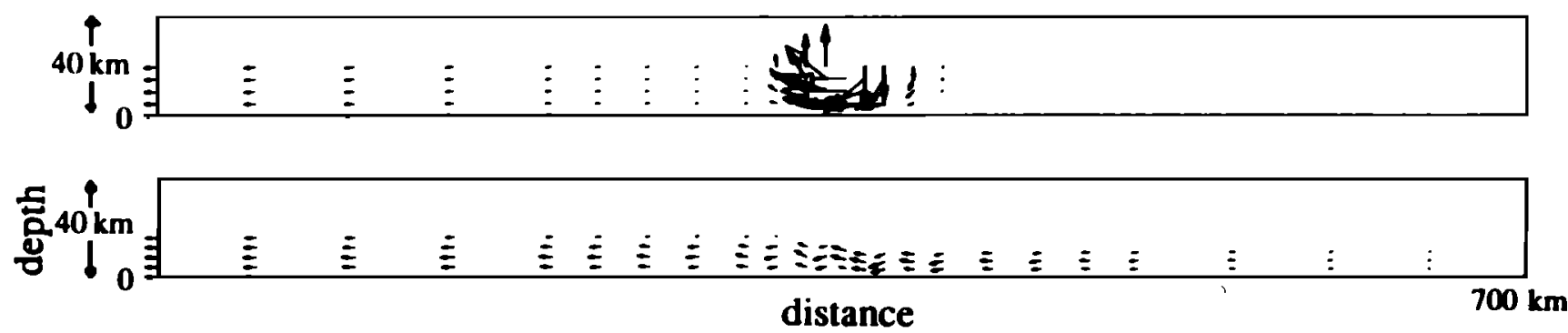

Fig. 12. Velocity vectors for flow in which the boundaries of the ductile channel are extending by a factor of 2 over the left side of the grid. Upper crustal thinning is assumed to be $1 \mathrm{~km} / \mathrm{m}$.y. Top plot shows flow at zero time associated with $1 \mathrm{~km}$ of instantaneous upper crustal thinning. Bottom plot shows flow 5 m.y. after the onset of extension.

or in terms of the deviatoric stress

$$
\mu_{e f f}=\frac{\left(\sigma_{1}-\sigma_{3}\right)^{(1-n)} \mathrm{e}^{Q /(R T)}}{2 A}
$$

where the parameters are as defined for equation (6) above.

By comparing effective viscosities for crustal rocks with the viscosities found in the linear viscous flow models above we can estimate the conditions under which power law flow can produce significant redistribution of crustal material. The linear viscous flow modeling above showed that viscosities of $10^{18} \mathrm{~Pa} \mathrm{~s}-10^{20} \mathrm{~Pa} \mathrm{~s}$ yield acceptable flow rates in channels $10-25 \mathrm{~km}$ thick with the Lake Mead regional boundary conditions. Tables 1 and 2 show the temperatures needed for crustal rocks to attain effective viscosities equal to these viscosities. The temperatures in Table 1 were calculated with equation (8), assuming total strains of 0.5 over 10 m.y., or a strain rate of $10^{-15} \mathrm{~s}^{-1}$, and experimentally determined coefficients $Q, A$, and $n$. Olivine is shown for comparison with mantle materials. Table 2 temperatures were computed using equation (9), equating the deviatoric stress with yield stresses of 1$10 \mathrm{MPa}$ expected in the lower crust (see Figure 6). Table 2 demonstrates that effective viscosities of $10^{19}-10^{20} \mathrm{~Pa} s$ may be attained at lower crustal temperatures of $700^{\circ}-1000^{\circ} \mathrm{C}$ (or less for wet quartzite). Higher temperatures are required for the lower viscosities necessary for sufficient flow rates through channels with thickness of 5-10 km.

Finite element modeling of power law flow confirms that elevated lower crustal temperatures $\left(700^{\circ}-1000^{\circ} \mathrm{C}\right)$ are necessary for acceptable flow rates within channels $25 \mathrm{~km}$ thick or less in the Lake Mead region, for the quartz diorite and quartzite rheologies. (See the appendix for a discussion of the finite element technique.) Under the boundary conditions assumed in this study the pattern of flow for power law rheologies may be quite similar to that of linear viscous flow. Figure 14 illustrates the flow pattern and resulting topography for a quartzite rheology (see Table 1) under boundary conditions identical to those for the linear viscous flow shown in Figures 9 and 10. The similarity between the power law and linear viscous flow results from the fact that variations in the effective viscosities within the ductile layer in the power law flow model are relatively small under the conditions modeled here; thus much of the flow takes place with an approximately uniform viscosity. For the flow illustrated in Figure 14, we assume upper crustal thinning occurs in discrete instantaneous increments of $1 \mathrm{~km}$ every $1 \mathrm{~m} . \mathrm{y}$. The differences between the effective viscosities computed at each element within the finite element grid are a maximum immediately after each $1 \mathrm{~km}$ increment of upper crustal thinning and decrease with time over the subsequent 1 m.y. The spatial variations in effective viscosities are generally less than a factor of two at $\mathbf{0 . 5}$ m.y. after each instantaneous increment of thinning, except for elements on the side boundaries of the grid. These results suggest that the flow rates computed for linear viscous flow are a good approximation to the flow rates expected for lower crustal deformation by power law mechanisms.

\section{DISCUSSION}

\section{Approximations in the Modeling}

By assuming a rigid lower boundary (or Moho) in the first set of models above we overestimated the lateral pressure gradients in the
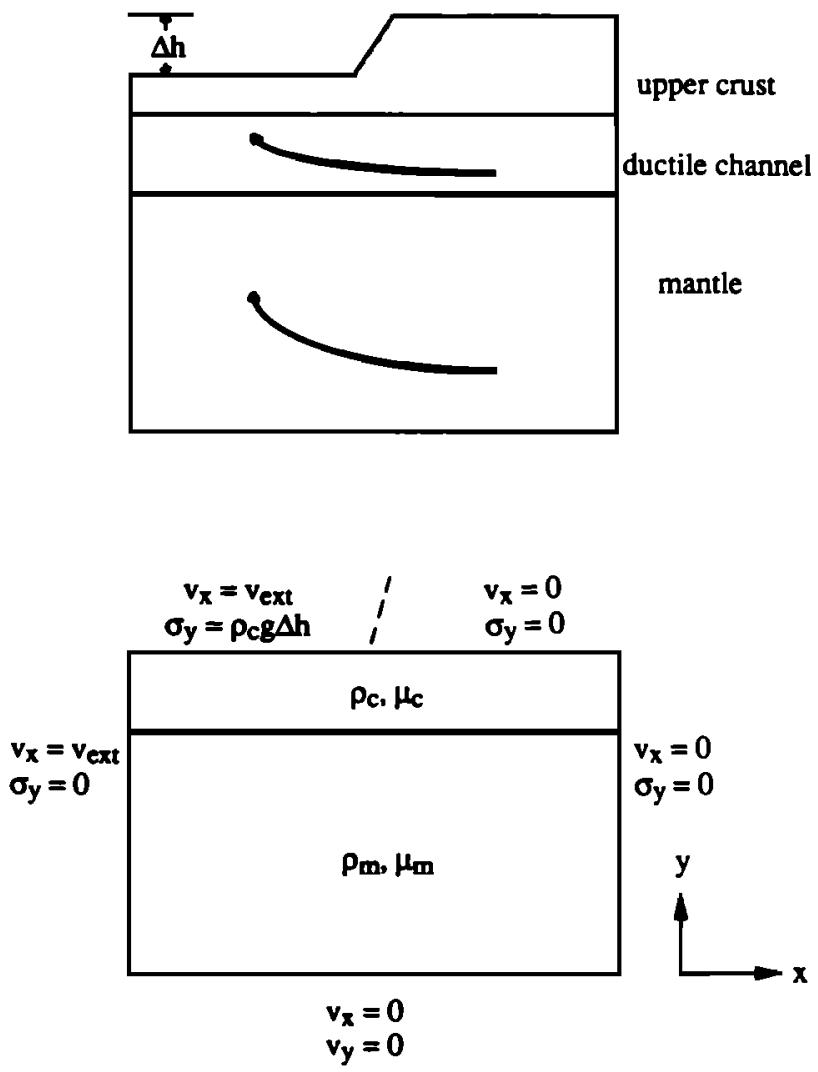

Fig. 13a. Boundary conditions for two-layer finite element model. 


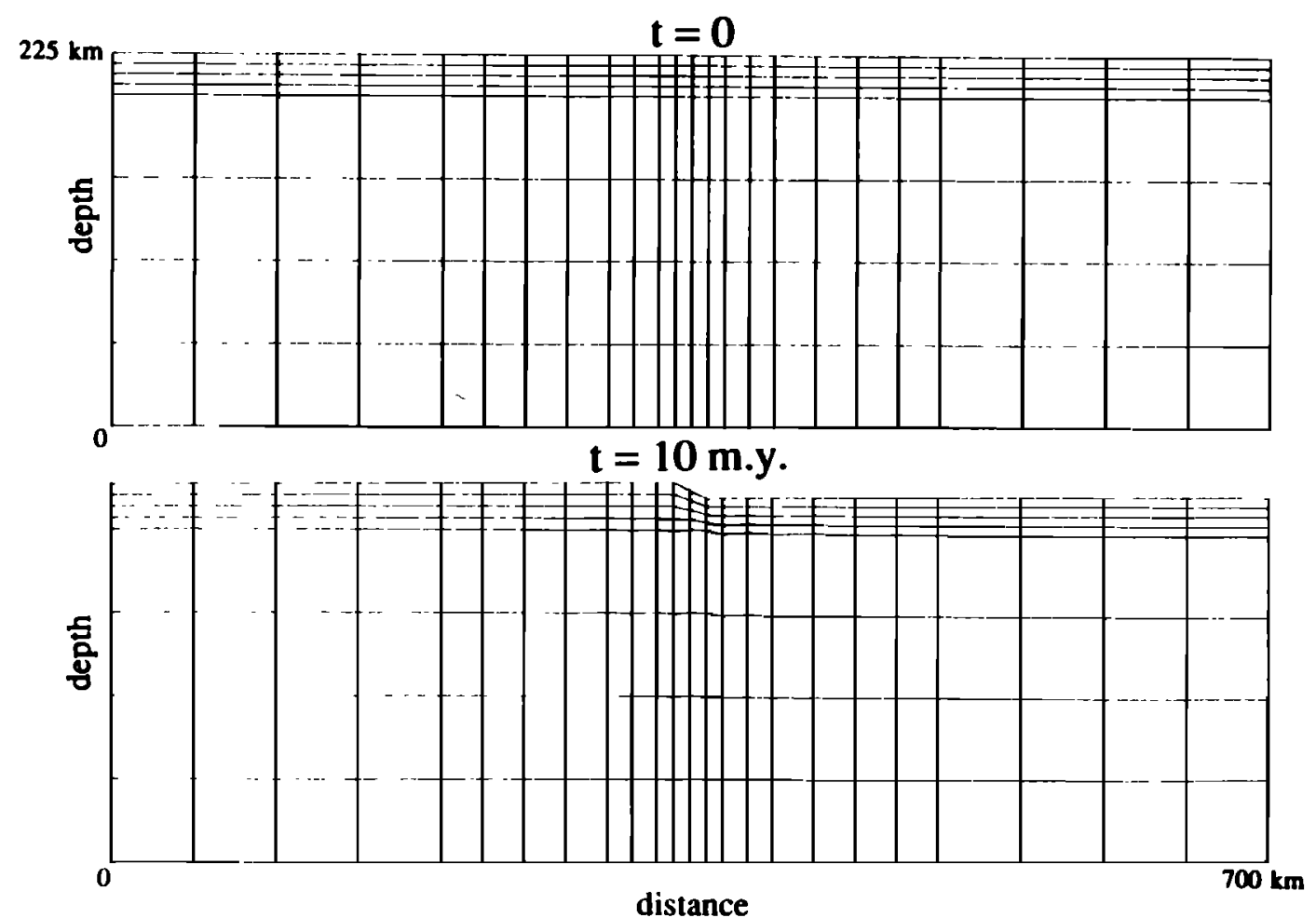

Fig. 13b. Finite element mesh used in two-layer modeling, prior to flow and after $10 \mathrm{~m}$.y. of flow with crustal channel viscosity of $10^{19} \mathrm{~Pa}$ s and mantle viscosity of $10^{21} \mathrm{~Pa}$ s. Lines connect nodes of nine-node elements. The example shown here is for a ductile crustal channel $25 \mathrm{~km}$ thick and a mantle layer $200 \mathrm{~km}$ thick.

ductile channel and neglected a kink that may be introduced into the channel at the transition zone as the Moho is deflected upward beneath the region of upper crustal thinning. Both observations are illustrated in Figure 15, assuming that mantle flow and Moho deflections completely compensate variations in crustal thickness. We expect the pressure gradients in an inviscid mantle model (Figure 15) to be smaller by a factor of $\left(\rho_{m}-\rho_{c}\right) / \rho_{m}$ than the gradients in the fixed lower boundary model. For $\rho_{m}=3300 \mathrm{~kg} / \mathrm{m}^{3}$ and $\rho_{c}=2700 \mathrm{~kg} / \mathrm{m}^{3}$ gradients should differ by a factor of 5 . However, we find as described in the finite element modeling above that the thickening of the lower crust beneath the thinned areas in the two-layer crust-mantle model is only $30 \%$ slower for a $25-\mathrm{km}$ - thick crustal channel, and only $50 \%$ slower for $10-\mathrm{km}$ thick channel. This apparently enhanced flow rate in the two-layer model sterns from the fact that lateral flow occurs on the crust-mantle boundary in these models (Figure 16). Flow in the crustal channel in the two-layer model may be better approximated by flow in a channel with a zero shear stress on the lower boundary, rather than with zero velocity along the lower boundary as assumed in the analytical approximation for channel flow discussed above. Flow rates in a channel of fixed thickness under equal pressure gradients are 4 times greater with zero shear stress than with zero velocity along the lower boundary. Considering both the difference in pressure gradients and the difference in flow along the lower

quartzite $\mathrm{T}=700^{\circ} \mathrm{C}$

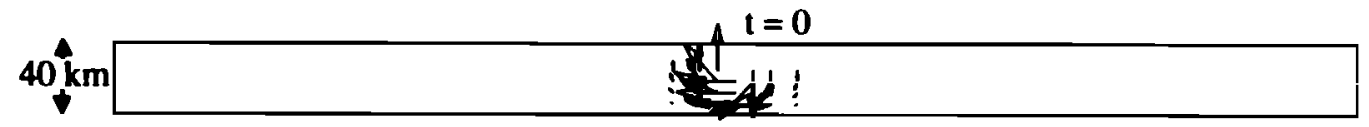

$\mathrm{t}=1.8 \mathrm{~m} . \mathrm{y}$.

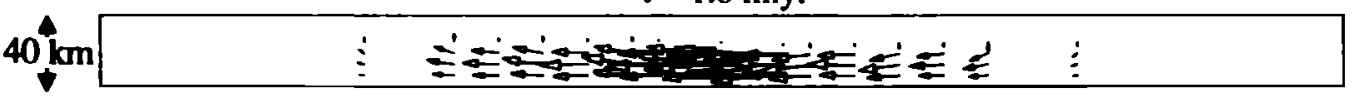

$t=5.5$ m.y.

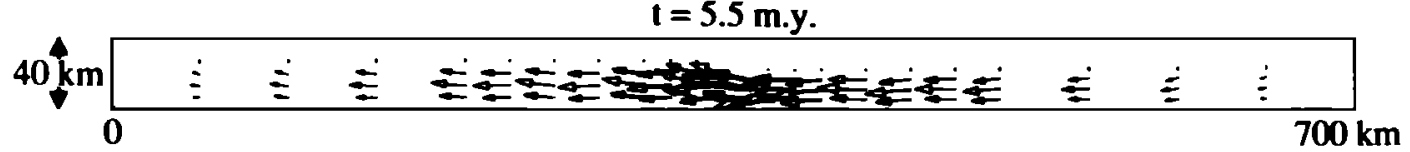

Fig. 14a. Velocity vectors for flow in a $25-\mathrm{km}$ thick channel assuming a quartzite theology with flow parameters as listed in Table 1 at times $0,1.8 \mathrm{~m} . y$. , and $5.5 \mathrm{~m} . \mathrm{y}$ after the onset of upper crustal thinning over the left side of the mesh at a rate of $1 \mathrm{~km} / \mathrm{m} . \mathrm{y}$. (Boundary conditions are identical to those assumed in Figure 9.). 


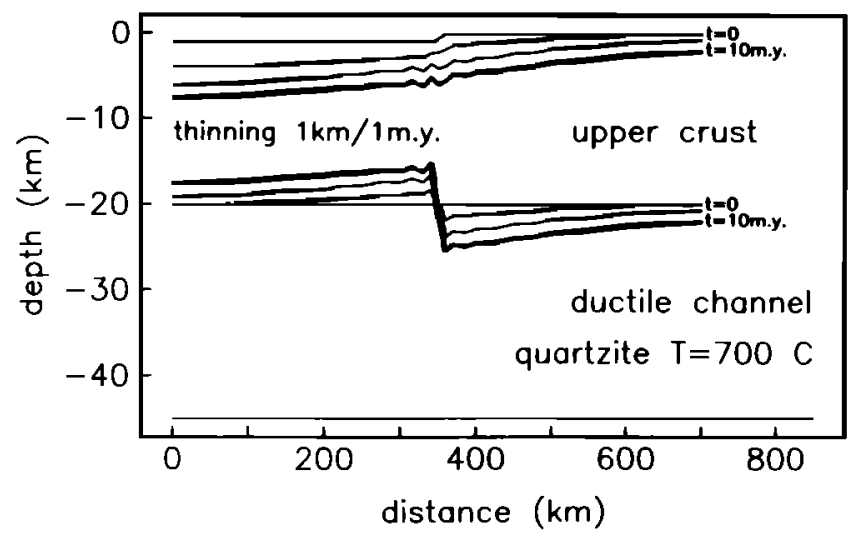

Fig. 14b. Variations in total crustal thickness and ductile channel thickness assuming a quartzite theology under conditions identical to those assumed in Figures 9 and 10.

boundary we expect flow rates in the two-layer models to be roughly $15 \%$ lower than in comparable one-layer models, which is close to the value we observe. The fixed lower boundary model thus appears to overestimate only moderately the maximum viscosities for models with channel thickness greater than $10 \mathrm{~km}$.

An offset in the channel at the transition zone is important in models where the size of the offset in the channel is comparable to the total thickness of the channel, and flow is pinched off at the transition zone. Assuming Moho deflections compensate upper crustal thinning, and neglecting crustal flow, the offset in the channel equals the mantle uplift $\Delta m$ which in tum equals the crustal thinning $\Delta h$ times the ratio of crustal and mantle densities $\left(\rho_{c} / \rho_{m}\right)$. The offset in the channel thus becomes important in choking off flow when the ductile layer thickness is comparable in size to the thinning in the upper crust. Thus the upper bounds on acceptable viscosities derived from the fixed lower boundary models are probably too large for models with channel thickness of 5 or $10 \mathrm{~km}$. Any flexural rigidity in the upper mantle or in the upper crust, however, will diminish the abruptness of an offset at the transition zone and the associated restriction of flow, as will a gradual increase in crustal thinning over a zone several tens of $\mathrm{km}$ wide.

In the modeling above we assume that crustal thiming occurred in $1-\mathrm{km}$ intervals every $1 \mathrm{~m} . \mathrm{y}$. over the last $10 \mathrm{~m} . \mathrm{y}$. Crustal extension in the Lake Mead area occurred principally between 18 and $10 \mathrm{Ma}$, although some extension may have taken place as recently as $5 \mathrm{Ma}$ [Anderson et al., 1972; Bohannon, 1984; Wernicke et al., 1988]. Equation (5) suggests that we have underestimated the upper bounds on acceptable viscosities for flow in the Lake Mead area by approximately one half, assuming that most of the upper crustal thinning occurred over 5-10 m.y. and ceased 5-10 Ma.

In our models of Lake Mead we assume that material flows over roughly $700 \mathrm{~km}$, thickening the lower crust over several hundred $\mathrm{km}$ in the eastern Basin and Range. The viscosities of acceptable flow models are roughly inversely proportional to the square of the length scale assumed, however, as can be seen in equation (5). A discussion of the effect of the length scale is deferred to the section below on flow beneath narrower regions of extension such as metamorphic core complexes.

The above models assume that the transition zone between the extended and unextended areas (the region over which crustal thinning decreases from its maximum value to zero) is $20 \mathrm{~km}$ wide. Finite element modeling of broader or narrower transition zones indicate that variations in the width of this zone have no significant impact on the derived upper bounds on acceptable viscosities.

The two-dimensional finite element models neglect ductile flow parallel to the transition zone. For example, the terrain north of Lake Mead between the Colorado Plateau and the Mormon Mountains-Muddy Mountains areas has undergone extension by a factor roughly half that at Lake Mead [Wernicke et al., 1988]. Thus southward lower crustal flow may have occurred between this region and the Lake Mead area. If the high heat flow values in the Basin and Range are interpreted to reflect elevated crustal temperatures, then flow within the Basin and Range may be facilitated by effective viscosities lower than in the adjacent Colorado Plateau. Consideration of three-dimensional flow may enhance effective flow rates into an extended region and hence raise the upper bounds on acceptable viscosities.

\section{Temperatures Associated With Lower Crustal Flow}

The experimentally derived flow parameters summarized in Tables 1 and 2 for crustal materials suggest that temperatures of the order of $700^{\circ}-1000^{\circ} \mathrm{C}$ are required to sustain the effective viscosities necessary for lower crustal flow over the $700 \mathrm{~km}$ length scale assumed near Lake Mead. These values, although highly dependent on the rheology assumed, are higher than the lower crustal/upper mantle temperatures of $500^{\circ}-800^{\circ} \mathrm{C}$ estimated by Lachenbruch and Sass [1978] on the basis of heat flow data over the Basin and Range. Slight elevations in crustal temperatures, however, may be quite effective in increasing ductile flow rates as they simultaneously reduce the effective viscosity and increase the thickness of the effective ductile channel by increasing the depth range over which

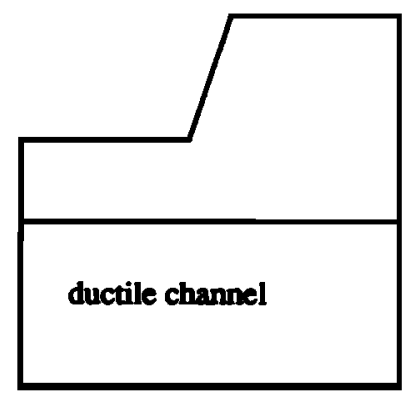

(t)

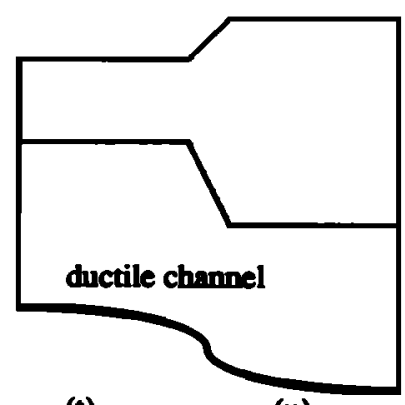

(t) (u)
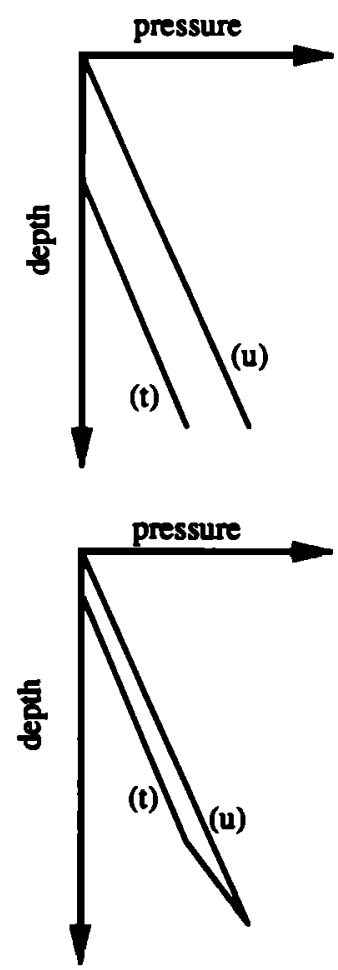

Fig. 15. Schematic illustration of difference in pressure gradients between rigid lower boundary (top plots) and two-layer models (lower plots). Overburden pressure as a function of depth is plotted for the unextended (u) and thinned region $(t)$. Average pressure gradients at a given depth correspond to the horizontal distnnce between the two lines. See text for discussion. 


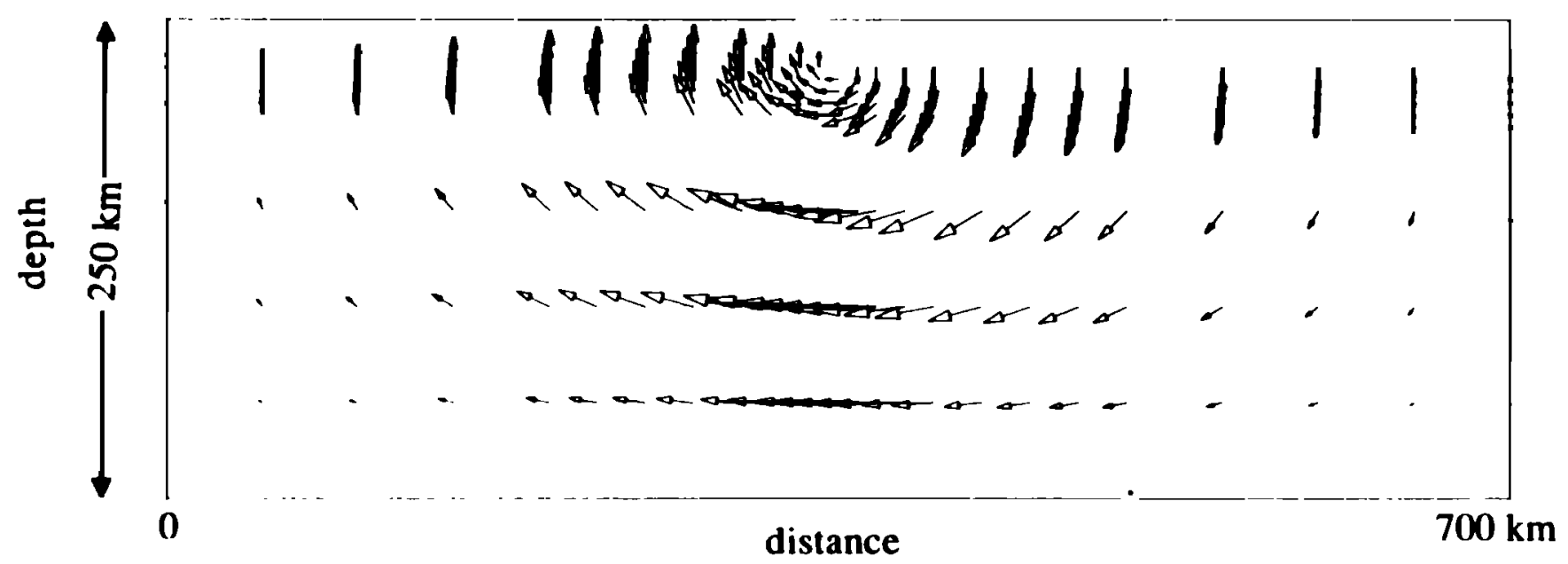

Fig. 16. Velocity vectors for flow in a two-layer model at time $\mathrm{t}=0$, assuming an an instantaneous upper crustal thinning of $1 \mathrm{~km}$ over the left side of the mesh. Shallower, closely spaced vectors mark velocities in a $25-\mathbf{k m}$ thick crustal channel with viscosity of $10^{20} \mathrm{~Pa} \mathrm{~s}$ and density of $2600 \mathrm{~kg} / \mathrm{m}^{3}$. Deeper, more widely spaced vectors show flow in the underlying $200-\mathrm{km}$ thick mantle channel with viscosity also $10^{20} \mathrm{~Pa}$ s and density of $3300 \mathrm{~kg} / \mathrm{m}^{3}$. A significant horizontal velocity is found at the crust-mantle boundary near the transition zone.

yicld stresses in the crust are small. We interpret these combined results as suggestive that ductile flow over the length scale assumed here is most likely to occur in thicker effective channels (of the order of $15-25 \mathrm{~km}$ ) where sufficient flow rates can be maintained at higher effective viscosities.

\section{Topography Across the Transition Zone}

Acceptable ductile flow models with 25-km channel thicknesses show a smooth variation in total crustal thickness across across the transition zone (see Figure 10). We expect comparably smooth variations in elevations across the transition zone if these crustal thickness variations are compensated at the Moho. Thus these models do not predict the abrupt change in topography observed at the Lake Mead transition zone, where elevations decrease about
$1000 \mathrm{~m}$ from the Colorado Plateau to the Basin and Range over a distance less than $70 \mathrm{~km}$.

Models for flow in channel $10 \mathrm{~km}$ thick will predict more abrupt changes in topography at the transition zone (Figure 17). Two additional altemative explanations for the observed shortwavelength change in elevation are considered here.

A difference in density between lower crustal rocks involved in ductile flow and the thinned upper crustal rocks could produce a change in elevation across the transition zone that is as abrupt as the change in crustal thinning. This is illustrated most simply by considering the case where flow of lower crustal material has gone "to completion" in the sense that lateral pressure gradients within the ductile layer are zero. In this case, if ductile channel and upper crustal densities are equal, then the volume and mass of material added to the lower crust in the extended region exactly equal the

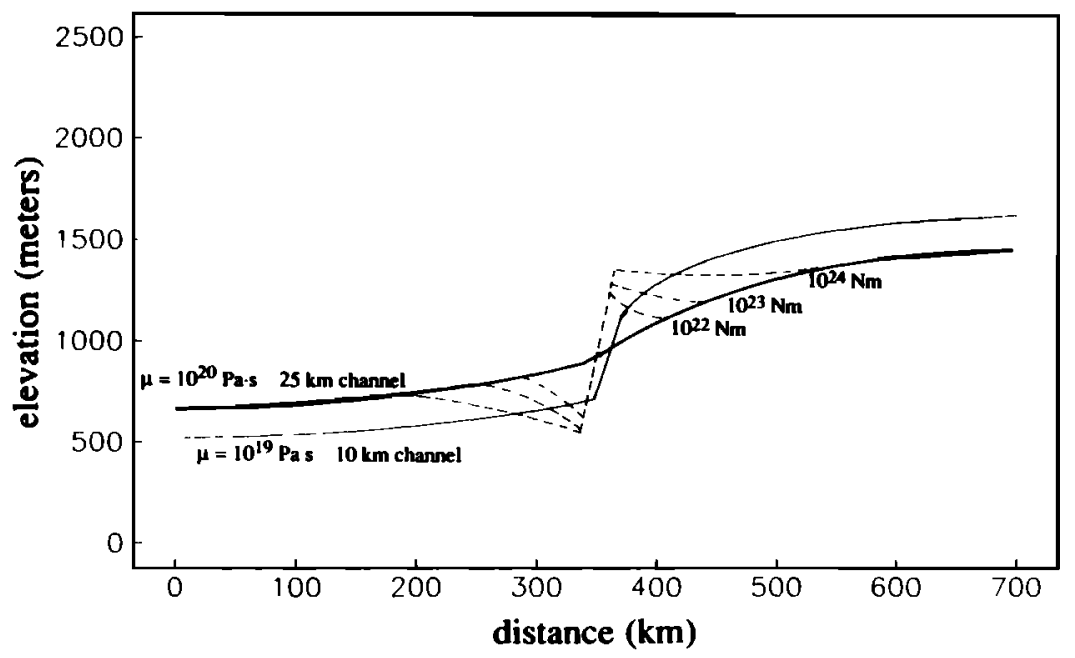

Fig. 17. Models for the topographic step across the transition zone. Dashed curves show the approximate shape of a flexurally maintained discontinuity in the topography superimposed on the sinooth topographic step predicted from linear viscous flow at $10^{20}$ $\mathrm{Pa}$ s for $10 \mathrm{~m} . \mathrm{y}$. The shape of the step is a function of the flexural rigidity. Thick solid curve shows the original $10^{20} \mathrm{~Pa}$ s ductile flow profile. Thin solid curve shows the topography after $10 \mathrm{~m}$.y. for flow at $10^{19} \mathrm{~Pa}$ s in a 10-km thick channel. The $100 \mathrm{~m}$ "jaggedness" in elevation produced by the finite element models has been removed. 


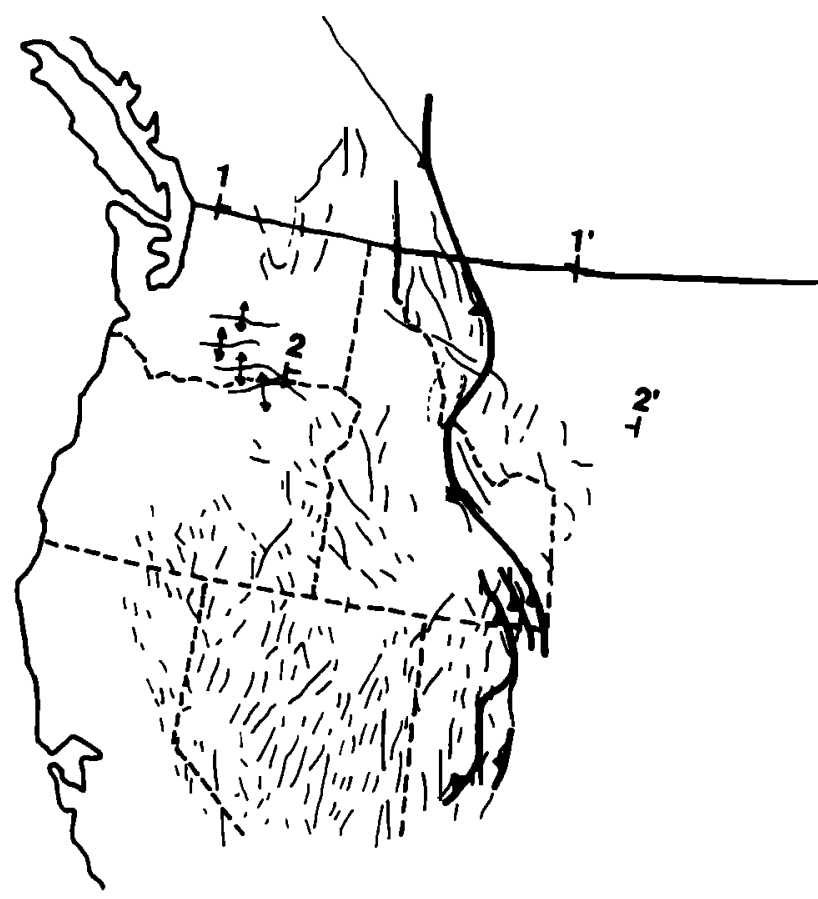

Fig. 18. Location map showing profiles $1-1^{\prime}$ and 2-2', boundary of Mesozoic thrusting, and Cenozoic normal faulting and related features. Ts mark the endpoints of profiles $1-1^{\circ}$ and 2-2'. Fine dashed lines show boundaries of areas of upper crustal extension along the profiles. Thick barbed line marks location of eastem boundary of Mesozoic thrusting. Thinner lines indicate Cenozoic normal faulss. volume and mass of upper crustal material removed during thinning and the crustal thickness is uniform. (We assume that the ductile channel itself is not actively extending, as in the top plot of Figure 10.) If, however, the ductile material has a higher density, then the volume added to the ductile layer is smaller than the amount removed by thinning. Elevations over the region of upper crustal thinning will then be lower since the net crustal thickness is smaller. The width of the transition in crustal thickness and in elevations will be the same as the width of the transition between the regions of unextended and thinned upper crust.

We can compute the density contrast between the ductile channel rocks and upper crustal rocks necessary to produce differences in elevation where lower crustal flow is still active, assuming that variations in the weight of crustal columns are compensated at the Moho. For example, a $1 \mathrm{~km}$ difference in elevation $\Delta e$ between the Basin and Range and Colorado Plateau requires a density contrast $\Delta \rho$ such that

$$
\Delta \rho=\frac{\rho_{m}(\Delta e-\Delta h+\Delta r)+\rho_{c}(\Delta h-\Delta r)}{\Delta r}
$$

where $\Delta h$ is the upper crustal thinning, $\Delta r$ is the ductile channel thickening, and $\rho_{m}$ and $\rho_{c}$ are mantle and upper crustal densities, respectively. For $10 \mathrm{~km}$ of upper crustal thinning and $5 \mathrm{~km}$ of thickening in the ductile channel in the extended region, we set $\Delta h=$ $10 \mathrm{~km}, \Delta r=5 \mathrm{~km}, \rho_{m}=3300 \mathrm{~kg} / \mathrm{m}^{3}$, and $\rho_{c}=2700 \mathrm{~kg} / \mathrm{m}^{3}$ and find $\Delta \rho=60 \mathrm{~kg} / \mathrm{m}^{3}$. Such a density contrast is within the range of densities of crustal materials.

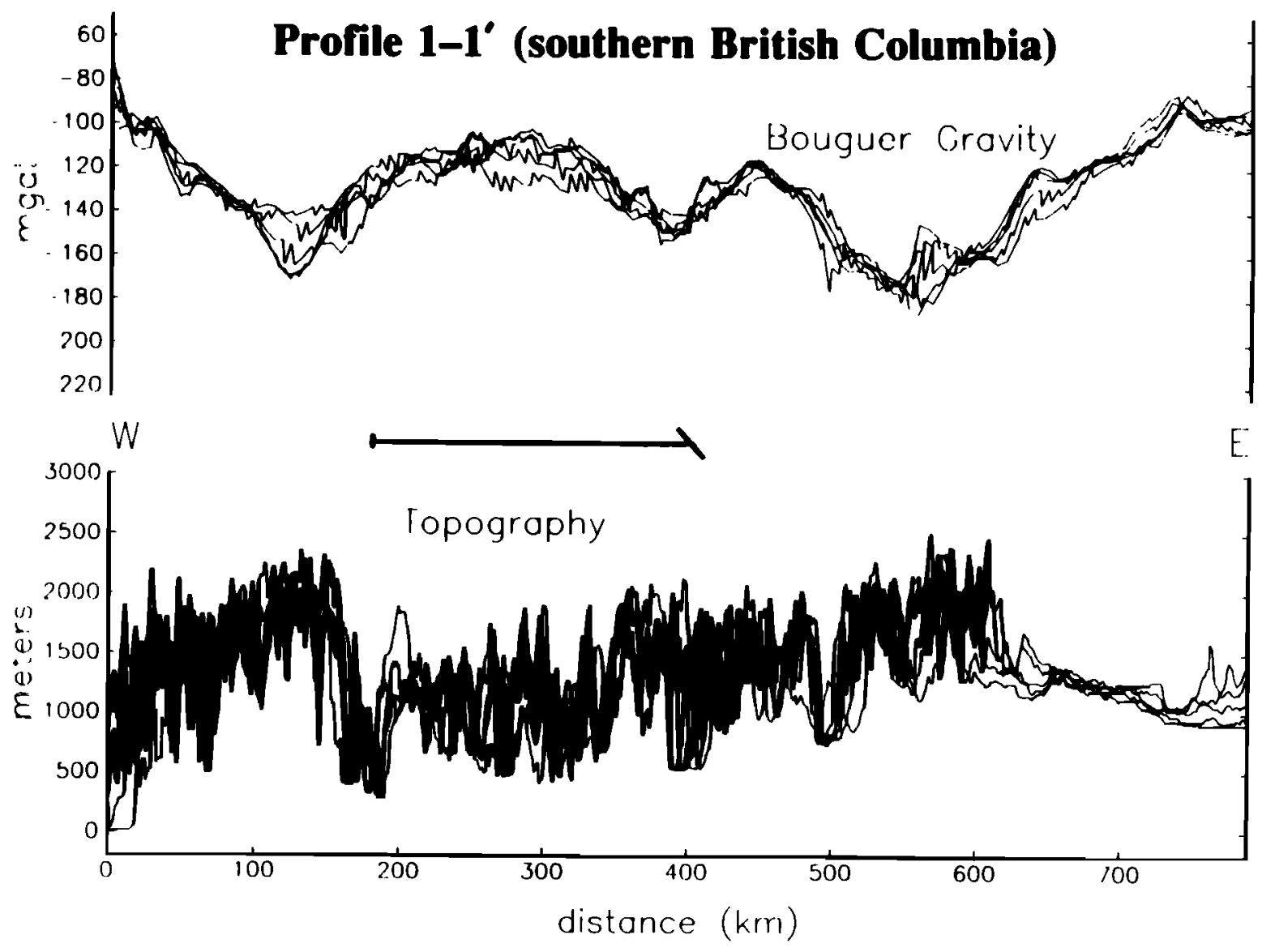

Fig. 19a. Bouguer gravity anomalies and topography along profiles roughly perpendicular to $\mathrm{N}-\mathrm{S}$ Eocene nomal faults in an extended region in southem British Columbia. Location shown in Figure 18. Horizontal line between plots indicates the location of the extended area. Diagonal line indicates the east dipping breakaway fault on the eastem margin. 

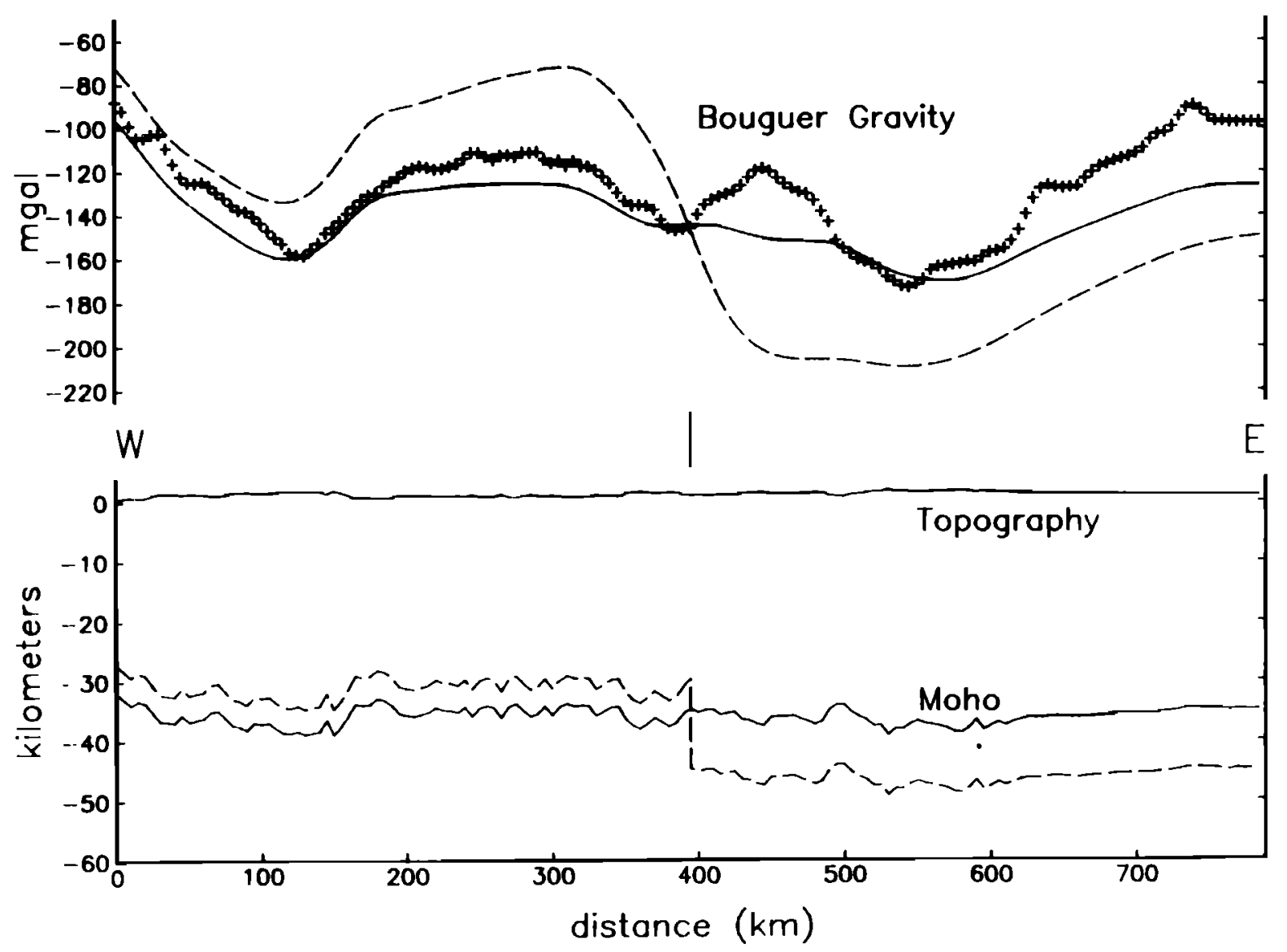

Fig.19b. Gravity models along Profile 1-1'. Crosses show observed Bouguer gravity anomalies averaged from the five profiles shown in Figure 19a. Solid curve shows simple Airy compensation model. Dashed curve assumes $15 \mathrm{~km}$ of crustal thinning is supported by a uniform $-50 \mathrm{~kg} / \mathrm{m}^{3}$ density anomaly extending to $205 \mathrm{~km}$ depth in the mantle beneath the thinned crust. Crustal and unextended manle densilies are assumed to be 2700 and $3300 \mathrm{~kg} / \mathrm{m}^{3}$, respectively. Local variations in topography are supported by deflections of the Moho superimposed on the abrupt crustal thinning.

The abrupt change in elevation at the transition zone could also be a structural offset that is maintained by crust with nonzero flexural rigidity. We can model such a topographic step, assuming compensation of the step by flexure over an inviscid crustal layer, without any infilling of the flexural relief (Figure 17). For flexural rigidities of the order of $10^{21}-10^{22} \mathrm{~N} \mathrm{~m}$ (corresponding to effective elastic plate thicknesses $T_{e}$ of $5-12 \mathrm{~km}$ ) and a step of approximately $1000 \mathrm{~m}$, this model predicts troughs approximately $100 \mathrm{~m}$ deep and about $100-150 \mathrm{~km}$ wide on both sides of the transition zone scarp. Such troughs are not apparent in the topography data across the Lake Mead transition, although the topography is locally quite rough. Therefore, if the topographic step is flexurally maintained, either flexural rigidities of the order of $10^{23} \mathrm{~N} \mathrm{~m}\left(T_{e}=25 \mathrm{~km}\right)$ are required, in which case the flanking troughs are reasonably small, or the topography between the troughs and the transition zone has been eroded from an initially greater step. A flexural rigidity of $10^{23} \mathrm{~N} \mathrm{~m}$ is greater, however, than values obtained by forward modeling of the gravity data above and coherence studies [Bechtel et al., 1990]. This suggests that $100 \mathrm{~m}$ or more of material has been eroded from the Grand Wash Cliffs, if the topographic step is principally flexurally maintained.

\section{Implications of the Ductile Flow Model for Older Transition Zones}

The ductile flow models predict (1) that lateral variations in total crustal thickness are smaller than expected from estimates of extension or unroofing and (2) that any variations in crustal thickness and in topography at transition zones should decrease with age after the cessation of extension, unless flow is inhibited by decreasing temperatures or if the density of lower crustal rocks is greater than that of rocks in the upper crust. These predictions are examined at two older breakaway faults on the eastern margin of the region of Cenozoic extension in western North America (Figure 18). Figures 19 and 20 show topography and gravity data and gravity modeling across Eocene age (40-55 Ma) breakaway zones in southern British Columbia and in northem Idaho.

Gravity modeling suggests the first prediction holds true along both profiles. Parrish et al. [1988] estimate extension west of the breakaway fault to be approximately $30 \%$, about half of which occurred between 50 and $60 \mathrm{Ma}$. In the absence of crustal flow, such extension of the entire crust predicts thinning of the order of 15 $\mathrm{km}$ over the extending region. The topography data require that the resulting $15-\mathrm{km}$ variation in crustal thickness be compensated by low-density material in the upper mantle. However, the gravity data require the contrast in mantle densities beneath thinned and unthinned crust to be more than $100 \mathrm{~kg} / \mathrm{m}^{3}$ (Figure 19b). A simple Airy compensation model with crustal thickness variations of the order of $5 \mathrm{~km}$ or less yields a much better fit to the gravity data. We note, however, that we cannot rule out several other possible explanations for these observations, including (1) initially thicker crust in the extended area, since the eastern limit of the late Cretaceous to Tertiary thrust faulting lies $150 \mathrm{~km}$ eastward of the 


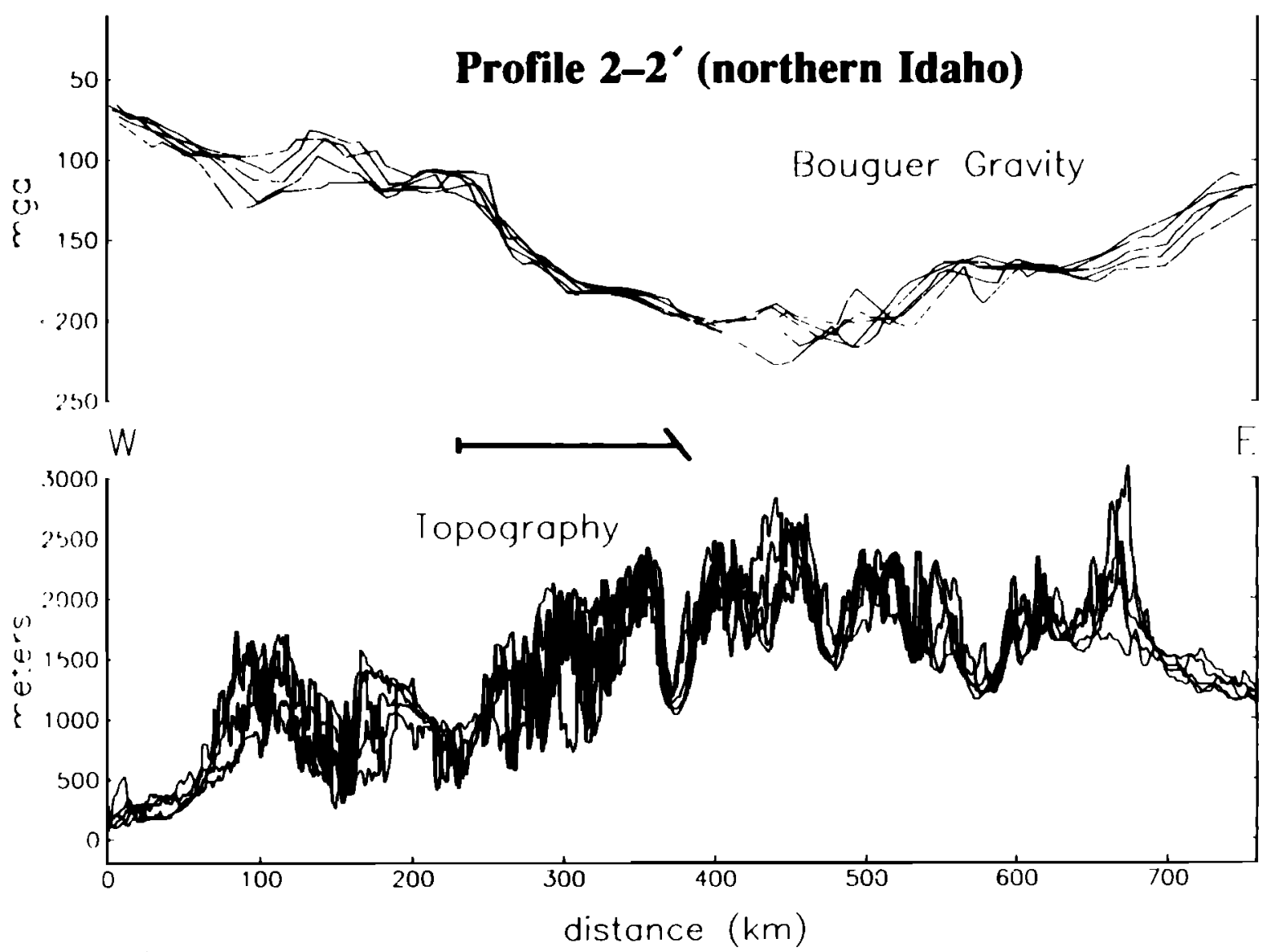

Fig. 20a. Bouguer gravity anomalies and topography along profiles roughly perpendicular to N-S Eocene normal faults near the Bitterroot batholith of northem Idaho. Location shown in Figure 18. Horizontal line between plots indicates the location of the extended area. Diagonal line indicates the east-dipping breakaway fault on the eastern margin.

breakaway fault [e.g., Miller et al., 1991], and (2) thinning of the region east of the surface outcrop of detachment faulting.

Similar modeling on profile 2-2' across northem Idaho suggests crustal thickness variations are smaller than $5-18 \mathrm{~km}$ of uplift estimated by Hyndman et al. [1988] for a metamorphic zone bounding the breakaway zone in the Bitterroot batholith. Figure $20 b$ shows that an intermediate estimate of crustal thinning of $12 \mathrm{~km}$ west of the breakaway fault cannot satisfy both gravity and topography data with reasonable lateral variations in mantle densities. As was the case in the Lake Mead area and in profile 1-1' in southem British Columbia, the gravity data are best fit assuming total crustal thickness variations less than geological estimates of crustal thiming in the extended area. Again, altemative mechanisms for explaining the apparent uniformity in crustal thickness may be viable, as the eastem limit of Cordilleran thrust belt lies some 200 km east of northem Idaho breakaway fault and the breakaway fault dips east.

The second prediction of the ductile flow model, that any variations in crustal thickness should diminish with time after extension, is born out in the topography profiles across the southern British Columbia breakaway zone. The change in elevation across this region is smaller than near the more recently active Lake Mead (Figure 19a). However, the change in elevation along the northern Idaho profile is comparable to that at Lake Mead. The amount of crustal thinning in northern Idaho was probably not greater than that at Lake Mead. Thus it appears that ductile flow subsequent to periods of extension may in some cases be inhibited, perhaps by an increase in viscosities associated with regional cooling, or by higher densities of lower crustal material. Elevations in this region may also have been modified more recently by Miocene extension. Better constraints on the crustal density and temperature structure, preextensional crustal thicknesses, and the amounts of crustal thiming are needed to resolve the causes of changes in topography across breakaway zones.

\section{Implications for Metamorphic Core Complexes}

Block and Royden [1990] have shown that the development of metamorphic core complexes, where rocks uplifted from midcrustal levels are exposed at the surface, must be accompanied by infilling from below of material with densities comparable to upper crustal densities, unless the crust in the region of uplift was substantially thicker prior to uplift. Their argument is based on seismic and gravity evidence that the Moho is presently flat beneath these regions [Allmendinger et al., 1987; Hauser et al., 1987]

In this study we examine the viscosities required for lower crustal infilling beneath the uplifted metamorphic core complexes by modifying the length scale in our models to a value of $150 \mathrm{~km}$, approximating the width of metamorphic core complexes. Figure 21 shows that the analytical channel flow approximation of equation (5), assuming a horizontal length scale of $150 \mathrm{~km}$ and a $10 \mathrm{~m} . \mathrm{y}$. time scale for flow. We find that viscosities of $10^{19}-10^{21} \mathrm{~Pa} s$ satisfy the analytical approximation for "complete" ductile channel thickening beneath thinned upper crust. The inverse squared dependence of the upper bound viscosity on the length scale 

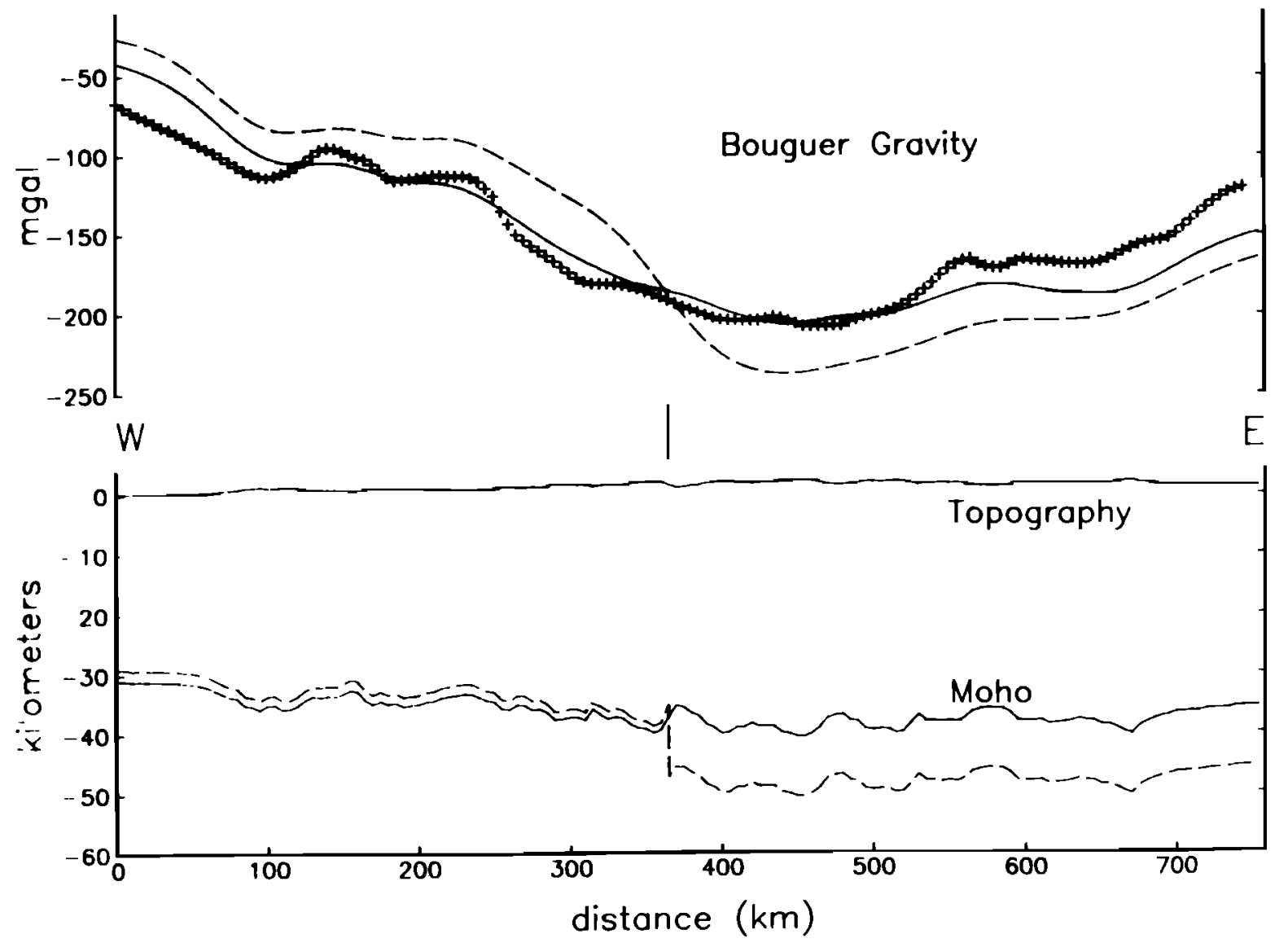

Fig. 20b. Gravity models along Profile 2-2'. Crosses show observed Bouguer gravity anomalies averaged from the five profiles shown in Figure 20a. solid curve shows simple Airy compensation model. Dashed line assumes $12 \mathrm{~km}$ of crustal thinning is supported by a uniform $-50 \mathrm{~kg} / \mathrm{m}^{3}$ density anomaly extending to $172 \mathrm{~km}$ depth in the mantle beneath the thinned crust. Crustal and unextended mantle densities are assumed to be 2700 and $3300 \mathrm{~kg} / \mathrm{m}^{3}$, respectively. Local variations in topography are supported by deflections of the Moho superimposed on the abrupt crustal thinning.

incrcases these values more than an order of magnitude from the viscosities calculated for $700 \mathrm{~km}$ of flow at Lake Mead.

Finite element modeling of flow over shorter length scales yields similar results. We model symmetric flow from two sides of a metamorphic core complex by modeling the "right half" of the flow and specifying the horizontal velocity to be zero over the center of the metamorphic core complex which is represented by the left boundary of the grid (shorter grid is shown in Figure 8a). The length of the unextended region (on the right side of the half-model) is set to $100 \mathrm{~km}$. The transition zone is assumed to be $20 \mathrm{~km}$ wide, and crustal thinning is again assumed to occur at a rate of $1 \mathrm{~km} / \mathrm{m} . y$. $(1 \mathrm{~mm} / \mathrm{yr}$ ) for $10 \mathrm{~m} . y$. Figure 21 illustrates the results of models for various viscosities and channel thicknesses, indicating whether the thickening of the ductile channel beneath the thinned region was more or less than $5 \mathrm{~km}$, or a "complete" $10 \mathrm{~km}$.

The higher acceptable viscosities for flow on the length scale of metamorphic core complexes correspond to temperatures in the ductile channel of the order of $500^{\circ}-700^{\circ} \mathrm{C}$ for the materials listed in Tables 1 and 2. Such temperatures are compatible with heat flow data over the Basin and Range [Lachenbruch and Sass, 1978], suggesting that flow beneath metamorphic core complexes as envisioned by Block and Royden [1990] is physically reasonable under the temperature and stress conditions associated with metamorphic core complex development. channel length $150 \mathrm{~km}$

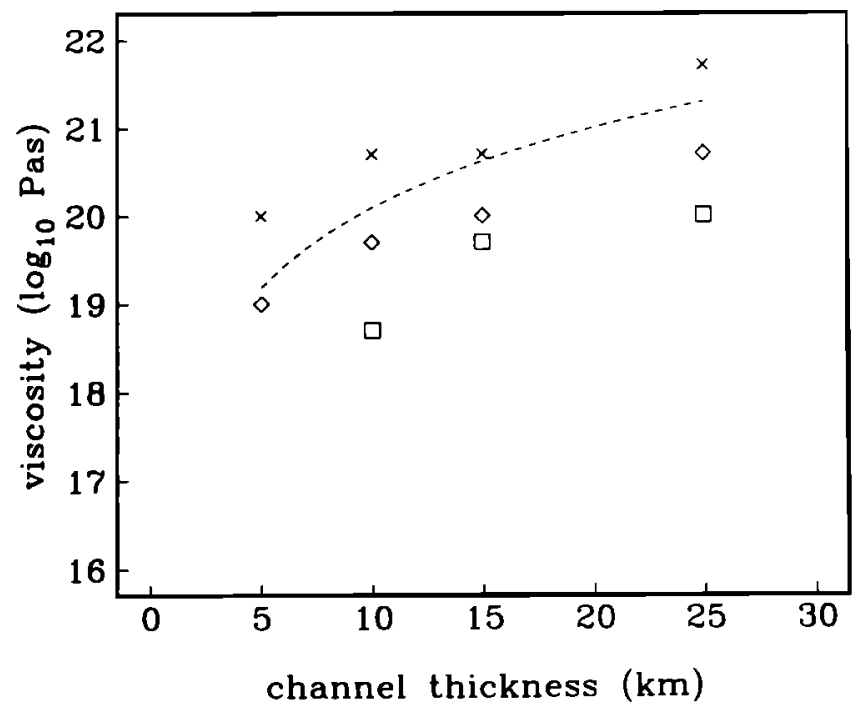

Fig. 21. Compilation of finite element and analytical modeling results for linear viscous flow assuming a channel length of $150 \mathrm{~km}$. Symbols as described for Figure 11. Finite element grid used is shown in Figure 8. 
TABLE 1. Flow Law Constants and Temperatures for flow at $10^{-15} \mathrm{~s}^{-1}$ Strain Rate

\begin{tabular}{lcccccc}
\hline & \multicolumn{3}{c}{ Flow law constants } & \multicolumn{3}{c}{ Temperatures Corresponding to Viscosity, ${ }^{\circ} \mathrm{C}$} \\
\cline { 2 - 7 } \multicolumn{1}{c}{ Malerial } & $\log _{10 A^{a}}$ & $\mathrm{n}$ & $\mathrm{Q}^{\mathrm{b}}$ & $10^{19} \mathrm{~Pa} \mathrm{~s}$ & $10^{20} \mathrm{~Pa} \mathrm{~s}$ & $10^{21} \mathrm{~Pa} \mathrm{~s}$ \\
\hline Quartzite & 1.9 & 2.9 & 149 & $>1500$ & 990 & 590 \\
Quartzite (wet) & 3.0 & 2.6 & 134 & 940 & 560 & 360 \\
Quartz dionite & 4.3 & 2.4 & 219 & 1150 & 820 & 620 \\
Westerly granite & 1.6 & 3.4 & 139 & $>1500$ & 1500 & 700 \\
Olivine & 4.8 & 3.5 & 533 & $>1500$ & $>1500$ & $>1500$ \\
\hline
\end{tabular}

$A$ in units of $\mathrm{GPa}^{-n} \mathrm{~s}^{-1}$.

b $Q$ in units of $\mathrm{kJ} \mathrm{mol}^{-1}$.

TABLE 2. Temperatures for Flow at 1-10 MPa Deviatoric Stress

\begin{tabular}{lrrrr}
\hline & \multicolumn{4}{c}{ Temperalures Corresponding to Viscosity, ${ }^{\circ} \mathrm{C}$} \\
\cline { 2 - 5 } Material & $10^{18} \mathrm{~Pa} \mathrm{~s}$ & $10^{19} \mathrm{~Pa} \mathrm{~s}$ & $10^{20} \mathrm{~Pa} \mathrm{~s}$ & $10^{21} \mathrm{~Pa} \mathrm{~s}$ \\
\hline Quartzite & $780-1140$ & $650-920$ & $550-760$ & $470-640$ \\
Quarzite (wet) & $500-660$ & $450-550$ & $350-460$ & $300-390$ \\
Quartz dionite & $790-940$ & $700-830$ & $620-730$ & $560-650$ \\
Westerly granite & $910->1500$ & $750-1270$ & $620-1000$ & $210-810$ \\
Olivine & $>1500$ & $>1500$ & $>1500$ & $>1500$ \\
\hline
\end{tabular}

See Table 1 for flow law constants.

\section{CONCLUSIONS}

Ductile flow in the lower crust driven by lateral pressure gradients associated with lateral variations in upper crustal thinning appears to be a viable mechanism for reconciling gravity and topography data and estimates of extension near Lake Mead, Nevada, but may require elevated temperatures (of the order $700^{\circ}-$ $1000^{\circ} \mathrm{C}$ ) in the lower crust. Other proposed models such as initially thicker crust in subsequently extended areas and mass transport on low-angle shear zones are incompatible with the geologic observations in the Lake Mead area. Ductile flow in response to lateral pressure gradients has an advantage over crustal underplating models in that ductile channel thickening correlates spatially with lateral variations in upper crustal thickness. Unlike models assuming lateral variations in mantle temperatures, this spatial correlation may be maintained even when variations in upper crustal thinning are abrupt, as is the case near Lake Mead.

Analytical approximations and finite element modeling of flow in a lower crustal channel show that the effective viscosities required for significant redistribution of lower crustal material are highly dependent on the thickness of the ductile channel and the length scale of the flow. Upper bounds on effective viscosities range from $10^{18}-10^{20} \mathrm{~Pa} \mathrm{~s}$ for ductile channels $10-25 \mathrm{~km}$ thick, respectively, for flow that yields $5 \mathrm{~km}$ or more of ductile channel thickening beneath $10 \mathrm{~km}$ of upper crustal thinning over the last $10 \mathrm{~m} . \mathrm{y}$. in the eastern Basin and Range near Lake Mead. Power law creep parameters derived for crustal material such as quartzite and quartz diorite imply that these effective viscosities correspond to temperatures $\left(700^{\circ}-1000^{\circ} \mathrm{C}\right)$ somewhat greater than those estimated from heat flow data.

Simple lower crustal ductile flow models fail to predict the abruptness of the change in topography at the Lake Mead transition zone as well as the amplitude of the change in topography across older (Eocene) breakaway zones in northern Idaho and British Columbia. The amplitude and wavelength of the topographic step between extended and unextended regions may reflect flexurally maintained structures and variations in intracrustal density structure as well as varying amounts of upper crustal thinning and lower crustal ductile flow.

Infilling of lower crustal material beneath metamorphic core complexes can occur at temperatures lower than those required for the flow modeled at Lake Mead. Ductile lower crustal flow driven by the pressure gradients associated with the unroofing of metamorphic core complexes is thus a plausible mechanism for explaining the flat Moho observed beneath the uplifted regions.

The good fit of the Airy compensation mechanism to the gravity data in the Lake Mead area suggests that compensation of topography occurs near Moho depths and thus that some lateral pressure gradients persist in the lower crust. Compensation in the mantle implies that mantle flow rates match or exceed ductile crustal flow rates. The strong dependence of flow rate on channel thickness indicates, however, that mantle flow rates may be greater than crustal rates even where effective mantle viscosities are greater than crustal viscosities. Thus the results here are compatible with asthenospheric viscosities of $10^{21} \mathrm{~Pa}$ s as derived from post glacial rebound studies [e.g., Peltier, 1986], if mantle flow occurs over a depth range of $50-100 \mathrm{~km}$ or more.

Seismic experiments in the Lake Mead transition zone and other parts of the Basin and Range which have undergone highly variable amounts of extension could improve both our resolution of deep crustal structure in these regions and our estimates of the conditions under which lower crustal ductile flow is significant.

\section{APPENDX}

\section{The Finite Element Technique}

Finite element computations were done with a modified version of the program FEM2D of Reddy [1984]. As a detailed description of the method is given by Reddy [1984], we focus here on adaptations of the program for the modeling described above. The momentum equation for two-dimensional Newtonian viscous flow is solved using nine-node quadrilateral elements with quadratic basis functions. Incompressibility is enforced at four Gaussian points within each element using a penalty function technique. A penalty parameter $\gamma=10^{8} \mu$, where $\mu$ is the viscosity, is used to separate the precision used to solve for shear strain components from that used to impose incompressibility. This method is equivalent to treating the fluid as a slightly compressible material with bulk modulus very large compared to shear modulus.

The pressure is evaluated at the Gaussian points where incompressibility is enforced. Body forces are computed at each node from element densities and interpolated over the elements using the element shape functions. Stress and velocity boundary 
conditions are imposed on the grid boundaries as discussed in the text (Figures 7 and 13).

We compute displacements by integrating velocities through time. Time steps were generally set so that the maximum displacement within a given interval did not exceed $250 \mathrm{~m}$. To alleviate problems associated with large displacements near the transition zone, we set a new mesh at the end of each time step. The nodes of the new mesh retain the horizontal coordinates of the nodes of the initial mesh (see Figure 8). The vertical displacements of nodes marking key horizons such as the upper and lower surfaces and a crust-mantle boundary are retained at the end of each time step. The new mesh is formed by linearly interpolating the $y$ values of the displaced nodes of the key horizons onto the new mesh. $Y$ coordinates of nodes between the key horizons are then set so that the vertical spacing of the new nodes within each column in a given layer is even. The finite element mesh at each time step thus does not record the cumulative deformation history of the original elements, but does record the change in the thickness of each layer as flow occurs within each time step.

We modified the above technique to model a power law stressstrain relation of the form of equation (6) above. The computation of stress and pressure from the viscosity and the derivatives of the velocities at the Gauss points within each element at each time step was replaced by the following sequence of calculations:

1. Set the viscosity to some initial guess (generally we used $10^{19}$ $\mathrm{Pa} s$ at all nodes) and compute a stiffness matrix and velocities and stresses at each node as done for Newtonian viscous flow.

2. Compute the deviatoric stress $\left(\sigma_{1}-\sigma_{3}\right)$ at each node, where $\left(\sigma_{1}-\sigma_{3}\right)$ is computed from the second invariant of the deviatoric stress tensor $\tau_{k l}$ such that $\left(\sigma_{1}-\sigma_{3}\right)=\left(\tau_{k l} \tau_{k l}\right)^{1 / 2}$.

3. Compute the effective viscosity at each node frotn the deviatoric stress based on the power law constitutive relation, where

$$
\mu_{\text {eff }}=\frac{\left(\sigma_{1}-\sigma_{3}\right)^{(1-n)_{\mathrm{e}} Q /(R T)}}{2 A}
$$

The coefficients $m Q$, and $A$ related to the material composition (see equation (6) in text for definitions) are assumed to be uniform throughout the ductile layer. The temperature $T$ is specified at each element. For the simple models discussed in this paper, $T$ is assumed to be uniform throughout the ductile layer and constant through time.

4. Update the viscosity at each element. To generate a stable solution the new trial viscosity is set to the average of the viscosity computed in the previous iteration and the new viscosity computed in step 3.

5. Set a new stiffness matrix based on the new viscosities at each element and find the velocities and stresses associated with the new stiffness matrix.

6. Compare the velocities with those computed in the last iteration; if the difference is greater than a specified criteria for convergence go to step 2, otherwise go to step 7 .

7. Once convergence is reached, compute displacements and update grid.

We defined a convergence criterion limiting the maximum change in a velocity on the grid in both $x$ and $y$ directions to less than $1 \%$ of the maximum $x$ and $y$ velocities, respectively, at the given iteration. Generally, between 5 and 30 iterations were required for convergence.

The approximately $100-\mathrm{m}$ undulations in $y$ values between adjacent nodes observed in the modeling above are representative of the resolution of the finite element technique. The jaggedness in the finite element solutions is characteristic of undersampling of flow near abrupt boundaries like the transition zone modeled here. Tests of the program against analytical solutions show that deformations with wavelengths greater than the spacing between two nodes are accurate representations of ductile flow and that the jaggedness increases with increasing coarseness in the mesh and sharpness in the transition zone. We chose a mesh sufficiently coarse that the computer programs ran reasonably fast, but fine enough that the spatial resolution (corresponding to the jaggedness) was good to approximately $100 \mathrm{~m}$.

Acknowledgments. Roger Buck was generous with his time and made suggestions that considerably strengthened this work. His support is gratefully acknowledged. Constructive reviews by Jon Spencer and Kevin Furlong significantly improved the manuscript. This work was supported in part by NASA NAG 5-1084 to M.M.

\section{REFERENCES}

Allmendinger, R.W., T.A. Hauge, E.C. Hauser, C.J. Pouer, S. L. Klemperer, K.D. Nelson, P. Knuepfer, and J. Oliver, Overview of the COCORP $40^{\circ} \mathrm{N}$ transect, westem United States: The fabric of an orogenic belt, Geol. Soc. Am. Bull., 98, 308-319, 1987.

Anderson, R.E., C.R. Longwell, R.L. Armstrong, and R.F. Marvin, Significance of K-Ar ages of Tertiary rocks from the Lake Mead region. Nevada-Arizona, Geol. Soc. Am. Bull., 83, 273-288, 1972.

Bechtel, T.D., D.W. Forsyth, V.L. Sharpton, and R.A.F. Grieve, Variations in the effective elastic thickness of the North American lithosphere, Nature, 343, 636-638, 1990.

Beghoul, N., and M. Barazangi, Mapping high $P n$ velocity beneath the Colorado Plateau constrains uplift models, J. Geophys. Res., 94, 70837104, 1989.

Block, L., and L. H. Royden, Core complex geometries and regional scale flow in the lower crust, Tectonics, 9, 557-567, 1990.

Bohannon, R.G., Nonmarine sedimentary rocks of Tertiary age in the Lake Mead region, southeastem Nevada and northwestem Arizona, U.S. Geol. Surv. Prof. Pap., 1259, 69 pp., 1984.

Bodell, J.M., and D.S. Chapman, Heat flow in the north-central Colorado Plateau, J. Geophys. Res., 87, 2869-2884, 1982.

Brace, W.F., and D.L. Kohlstedt, Limits on lithospheric stress imposed by laboratory experiments, J. Geophys. Res., 85, 6248-6252, 1980.

Buck, W.R., Flexural rotation of normal faults, Tectonics, 7, 959-973, 1988.

Burchfiel, B.C., R.J. Fleck, D.T. Secor, R.R. Vincelette, and G.A. Davis, Geology of the Spring Mountains, Nevada, Geol. Soc. Am. Bull., 85, 1013-1022, 1974.

Carter, N.L. and M.C. Tsem, Flow properties of continental lithosphere, Tectonophysics, 136, 27-63, 1987.

Coney, P.J., and T.A. Harms, Cordilleran metamorphic core complexes: Cenozoic extensional relics of Mesozoic compression, Geology, 12, 550-554, 1984.

Dewey, J.F., Extensional collapse of orogens, Tectonics, 7, 1123-1140, 1988.

Dunbar, J.A., and D.S. Sawyer, How preexisting weaknesses control the style of continental breakup, J. Geophys. Res., 94, 7278-7292, 1989.

Furlong, K.P., and D.M. Fountain, Continental crustal underplating: Thermal considerations and seismic-petrologic consequences, $J$. Geophys. Res., 91, 8285-8294, 1986.

Gans, P.B., An open-system, two-layer crustal stretching model for the eastem Great Basin, Tectonics, 6, 1-12, 1987.

Goetze, C., and B. Evans, Stress and temperature in the bending lithosphere as constrained by experimental rock mechanics, Geophys. $J$. R. astr. Soc., 59, 463-478, 1979.

Hauser, E.C., and J. Lundy, COCORP decp reflections: Moho at $50 \mathrm{~km}$ (16 s) beneath the Colorado Plateau, J. Geophys. Res., 94, 7071-7081, 1989.

Hauser, E.C., J. Gephart, T. Latham, J. Oliver, S. Kaufman, L. Brown, and I. Luccitta, COCORP Arizona transect: Strong crustal reflections and offset Moho beneath the transition zone, Geology, 15, 1103-1106, 1987.

Holt, W.E., C.G. Chase, and T.C. Wallace, Crustal structure from threedimensional gravity modeling of a metamorphic core complex: A model 
for uplift, Santa Catalina-Rincon mountains, Arizona, Geology, 14, 927-930, 1986

Hyndman, D.W., D. Alt, and J.W. Sears, Post-Archean metamorphic and tectonic evolution of western Montana and northern Idaho, in Metamorphism and Crustal Evolution of the Western United States, pp. 332-361, Rubey Volume 7, edited by W.G. Emst, Prentice-Hall, Englewood Cliffs, N.J., 1988.

Kirby, S.H., Rheology of the lithosphere, Rev. Geophys., 21, 1458-1487, 1983.

Lachenbruch, A.H. and J.H. Sass, Models of an extending lithosphere and heat flow in the Basin and Range province, in Cenozoic Tectonics and Regional Geophysics of the Westem Cordillera, edited by R.B. Smith and G.P. Eaton, Geol. Soc. Am. 152, 209-250, 1978.

Mayer, L., Topographic constraints on models of lithospheric stretching of the Basin and Range province, westem United States, in Extensional Tectonics of the Southwestern United States: A Perspective on Processes and Kinematics, edited by L Mayer, Spec. Pap. Geol. Soc. Am. 208, 1-14, 1986.

McCarthy, J. and G.A. Thompson, Seismic imaging of extended crust with emphasis on the westem United States, Geol. Soc. Am. Bull., 100. 1361-1374, 1988.

McKenzie, D., Some remarks on the development of sedimentary basins, Earth Planet. Sci. Lett., 40, 25-32, 1978.

McKenzie, D., Gravity currents in the lower crust, Geol. Soc. News., 17, 12, 1988.

Miller, D.M., T.H. Nilsen, and W.L. Bilodeau, Late Cretaceous to early Eocene geology of the U.S. Cordillera: Eastward migration of igneous and tectonic activity, in The Geology of North America, vol.xx, The Cordilleran Orogen: Conterminous U.S., edited by B.C. Burchfiel, P. Lipman, and M. Zoback, Geological Society of America, Boulder, CO., in press, 1991

Okaya, D.A., and G.A. Thompson, Involvement of deep crust in extension of Basin and Range province, in Extensional Tectonics of the Southwestem United States: A Perspective on Processes and Kinematics, edited by L. Mayer, Spec. Pap. Geol. Soc. Am. 208, 15-21, 1986.

Parrish, R.R., S.D. Carr and D.L Parkinson, Eocene extensional tectonics and geochronology of the southem Ominec Belt, British Columbia and Washington, Tectonics, 7, 181-212, 1988.

Peltier, W.R., Deglaciation-induced vertical motion of the North American continent and transient lower mantle theology, J. Geophys. Res., 91 , 9099-9213, 1986.

Price, R.A., The Cordilleran foreland thrust and fold belt in the southem Canadian Rocky Mountains, in Thrust and Nappe Tectonics, edited by K.R. McClay and N.J. Price, pp. 427-448, Geological Society of London, 1981.

Reddy, J.N., An Introduction to the Finite Element Method, 495 pp., McGraw-Hill, New York, 1984.

Rowley, P.D., J.J. Anderson, P.L. Williams, and R.J. Fleck, Age of structural differentiation between the Colorado Plateaus and Basin and Range provinces in southwestem Utah, Geology, 6, 51-55, 1978.
Smith, R.B., and R.L. Bruhn, Intraplate extensional tectonics of the eastem Basin-Range: Inferences on structural style from seismic reflection data, regional tectonics, and thermal-mechanical models of brittle-ductile deformation, J. Geophys. Res., 89, 5733-5762, 1984.

Sonder, LJ., P.C. England, B.P. Wernicke, and R.L. Christiansen, A physical model for Cenozoic extension of western North America, in Continental Extensional Tectonics, edited by M.P. Coward, J.F. Dewey, and P.L. Hancock, , Geol. Soc. Spec. Publ. London 28, 187-201, 1987.

Spencer, J.E. and S.J. Reynolds, Mid-Tertiary crustal extension in Arizona, Geol. Soc. Am. Abstr. with Programs, 16, 664, 1984.

Spencer, J.E. and S.J. Reynolds, Middle Tertiary tectonics of Arizona and adjacent areas, in Geologic Evolution of Arizona, edited by J.P. Jenney and S.J. Reynolds, Ariz. Geol. Soc. Dig., 17, 539-574, 1989.

Thompson, G.A., and J. McCarthy, Geophysical evidence for igneous inflation of the crust in highly extended terranes, Eos Trans. AGU, 67, $1184,1986$.

Thompson, G.A., and M.L. Zoback, Regional geophysics of the Colorado Plateau, Tectonophysics, 61, 149-181, 1979.

Turcotte, D.L., and G. Schubert, Geodynamics, 450 pp., John Wiley, New York, 1982.

Wemicke, B., Uniform-sense normal simple shear of the continental lithosphere, Can. J. Earth. Sci., 22, 108-125, 1985.

Wemicke, B., The fluid crustal layer and its implications for continental dynamics, in Exposed Cross-Sections of the Continental Crust, edited by M. Salisbury and D. Fountain, Kluwer Academic, Boston, Mass., 1990.

Wemicke, B., and GJ. Axen, On the role of isostasy in the evolution of normal fault systems, Geology, 16, 848-851, 1988.

Wernicke, B., G.J. Axen and J.K. Snow, Basin and Range extensional tectonics at the latitude of Las Vegas, Nevada, Geol. Soc. Am. Bull. 100, 1738-1757, 1988.

S. Kruse, Physics Department, Eckerd College, 4200 54th Ave. S, St. Petersburg, FL 33711.

M. McNutt and L. Royden, Department of Earth, Atmospheric, and Planetary Sciences, Massachusetts Institute of Technology, Cambridge, MA 02139.

J. Phipps Morgan, IGPP, A-025, Scripps Institution of Oceanography, La Jolla, CA 92093

B. Wernicke, Department of Geological Sciences, Harvard University, Cambridge, MA 02138.
Received February 13, 1990, revised November 12, 1990; accepted July 27,1990 .) 